\title{
CHUG-CHUG EN EL CONTEXTO DE LA MOVILIDAD INTERNODAL PREHISPÁNICA EN EL DESIERTO DE ATACAMA, CHILE
}

\author{
CHUG-CHUG IN THE CONTEXT OF PRE-HISPANIC INTERNODAL MOBILITY, \\ IN THE ATACAMA DESERT, CHILE
}

\author{
Gonzalo Pimentel G. ${ }^{1}$, Mariana Ugarte F. ${ }^{2}$, Francisco Gallardo ${ }^{3}$,
} José F. Blanco ${ }^{4,5}$ y Claudia Montero ${ }^{2}$

\begin{abstract}
El sector de Chug Chug destaca arqueológicamente por ser un espacio de gran relevancia para el estudio de la movilidad internodal en el desierto de Atacama. Lo que conocemos como Ruta de Chug-Chug correspondió a una de las principales vías interregionales que conectaba el norte del desierto de Atacama con el sur de los Andes occidentales, siendo uno de los corredores longitudinales más usados para activar las conexiones entre las sociedades tarapaqueñas y atacameñas desde el período Formativo en adelante. En el presente artículo damos cuenta de los resultados generales de nuestras investigaciones en el sector desde el año 2008, evaluando y discutiendo su relevancia macrorregional en la comprensión de las dinámicas de movilidad e intercambio entre las sociedades prehispánicas que cohabitaron las regiones de Tarapacá y el área atacameña en los últimos 2.500 años de la historia prehispánica (ca. 1000 a.C.-1550 d.C.).
\end{abstract}

Palabras claves: Chug-Chug, movilidad internodal prehispánica, intercambio interregional, geoglifos, desierto de Atacama.

The Chug-Chug area stands up in archaeological terms because it is highly relevant for the study of internodal mobility in the Atacama Desert. What is known as the Chug-Chug Route was one of the main inter-regional caravan roads connecting the north of the Atacama Desert with the southern part of the western Andes. It was one of the most frequently used longitudinal corridors to activate connections, particularly between the Tarapaqueña and Atacameña societies, from the Formative Period onwards. The present article reports the general results of our research in the area since 2008, assessing and discussing its macro-regional importance for understanding the dynamics of mobility and exchange between the pre-Hispanic societies which co-existed in the Tarapacá and Atacama regions in the last 2,500 years of pre-Hispanic history (ca. 1000 BC-1550 AD).

Key words: Chug-Chug, pre-Hispanic internodal mobility, interregional exchange, geoglyphs, Atacama Desert.

La "Ruta de Chug-Chug" corresponde a un rasgo arqueológico lineal que involucra decenas de kilómetros de continuidad de materiales, estructuras y figuras de geoglifos, dejados por los antiguos viajeros transdesérticos en sus desplazamientos entre los oasis de Calama y Quillagua. Fue también, en una escala mayor, un corredor central para las conexiones longitudinales más amplias entre Tarapacá y Atacama y entre otras regiones del Perú y Chile, dado su largo e intensivo uso en un eje norte-sur desde tiempos prehispánicos. Destaca además por contar con la mayor cantidad de geoglifos de la región de Antofagasta, un tipo de manifestación visual que se ha vinculado en esta región con las poblaciones tarapaqueñas del período Intermedio Tardío, asumiéndose como parte de una expansión meridional hacia Atacama del Estilo Pintados reconocido para el complejo cultural Pica-Tarapacá ${ }^{1}$ (Briones 2006; Núñez 1984). En ese sentido, ChugChug nos debía mostrar privilegiadamente estas relaciones interregionales, de modo de situar su rol particular como espacio de tránsito macrorregional y diacrónico. Especialmente consideramos que nos permitiría obtener una aproximación internodal a las relaciones de interacción y a las dinámicas societales entre las poblaciones de las áreas tarapaqueñas y

\footnotetext{
Instituto de Arqueología y Antropología, Universidad Católica del Norte, San Pedro de Atacama, Chile. gepimentel@ucn.cl Fundación Desierto de Atacama, Santiago, Chile.mugarte@desiertoatacama.com; cmontero@desiertoatacama.com

3 Centro Interdisciplinario de Estudios Interculturales e Indígenas, Pontificia Universidad Católica de Chile, Santiago, Chile. fgallardo.ibanez@gmail.com

4 Departamento de Antropología, Facultad de Ciencias Sociales, Universidad Alberto Hurtado, Chile.

5 Programa de Doctorado en Arqueología, Universidad Nacional del Centro de la Provincia de Buenos Aires (UNICEN), Olavarría, Argentina.jfblanco@gmail.com
} 
atacameñas, particularmente a partir del 900 d.C., cuando arqueológicamente se reconoce el inicio de una época de conflictos endémicos generalizados en todos los Andes y a los que no escapó el desierto de Atacama (p.ej. Berenguer 2004; Nielsen 2001, 2007). Analizar las relaciones entre sociedades productiva y políticamente similares, pero asimismo diferenciadas identitariamente a través de elementos materiales como la vestimenta y alfarería (p.ej. Agüero 2015; Uribe 2006), como fue el caso de las áreas tarapaqueñas y atacameñas en el período Intermedio Tardío, nos permite ampliar la mirada de las dinámicas de interacción entre sociedades más propias del desierto y de las cuales aún conocemos muy poco. Con estos antecedentes generales, cabía preguntarse ¿qué revelará Chug-Chug sobre la profundidad cronológica de su contexto de tránsito y sobre las características de los viajes según las distintas épocas?, ¿qué relaciones y dinámicas societales se reconocerían en ChugChug, particularmente entre las sociedades que cohabitaron las áreas tarapaqueñas y atacameñas? En el presente trabajo entregamos una síntesis de los principales resultados obtenidos en Chug-Chug, quedando pendiente una discusión más ampliada.

Como podremos profundizar, Chug-Chug fue un espacio consolidado de tránsito caravanero desde tiempos formativos, cuyo uso continuó interrumpidamente hasta mediados del siglo XX. Reconocimos 35 sitios estructurados, de los cuales 30 son de tiempos prehispánicos, cinco que comparten ocupaciones prehispánicas e históricas: tres son exclusivamente históricos y dos, de cronología incierta. Además de toda una diversidad de bienes muebles, los que se hallaron a veces en contextos con significancia particular, pero la gran mayoría como simples elementos abandonados sobre la vía. De los bienes muebles, lo más representado fueron los hallazgos de fragmentos cerámicos $(n=33$ puntos), y como conjunto destacan los materiales históricos, principalmente de la época salitrera (p.ej., restos óseos de vacuno y equinos, botellas de vidrio, metales). Aquí nos concentraremos exclusivamente en las evidencias prehispánicas, las que abordaremos según los distintos tipos de contextos y expresiones materiales.

\section{La Ruta de Chug-Chug en Contexto}

El sector de Chug-Chug se ubica en la cordillera del Medio o el Cordón del Cobre, específicamente entre la serranía de Montecristo, al norte del oasis de Calama, y el extremo noroeste de la quebrada de Chug-Chug, donde se inicia el plano inclinado de la Depresión Intermedia. Lo que denominamos Ruta de Chug-Chug comprende una vía internodal de unos $110 \mathrm{~km}$ de longitud, que es la distancia que se debía recorrer para conectar a pie las localidades de Quillagua y Calama. Se trata de una vía de senderos troperos compuesta por múltiples sendas, con un ancho total de hasta $160 \mathrm{~m}$ y con hasta 62 sendas paralelas.

Saliendo desde la localidad de Calama, la vía se reconoce en un plano inclinado al este de los cerros de Quetena, por la que se sigue hasta la serranía de Montecristo, y conectando por el lado norponiente con la serranía de Chug-Chug, donde se ubican los principales geoglifos de la región (Figura 1). Luego se continúa hasta la pequeña y semisalobre aguada de Chug-Chug, y se avanza por el interior de dicha quebrada hasta el extremo oeste de la Cordillera del Medio. Un poco antes de entrar a la Depresión Intermedia la vía se bifurca en dos direcciones. Por un lado, se sigue hacia el noroeste hasta la localidad de Quillagua, y luego aparece en el lado norte del río Loa para comunicar con Caleta Huelén, en la desembocadura del río Loa, y hacia el norte con Tarapacá. El otro ramal, en tanto, corre en un eje relativamente recto hacia el oeste hasta la pampa El Toco, Paso Galenosa y cordillera de la Costa, conectando finalmente con la costa de Tocopilla. Parte de esta conexión y algunos de sus sitios han sido referenciados previamente (Briones 2006; Briones y Castellón 2005; Correa y García 2014; Núñez et al. 2003; Pimentel 2009, 2011; Pimentel y Montt 2008). Cabe destacar que este trayecto es el eje más recto entre Calama y Quillagua, pero implica atravesar un inhóspito desierto absoluto con dos tramos especialmente críticos sin posibilidad de obtener agua: Calama-Aguada Chug-Chug con $45 \mathrm{~km}$ y Aguada Chug-Chug-río Loa con $48 \mathrm{~km}$.

En este trabajo consideramos el análisis de un segmento vial de unos $45 \mathrm{~km}$ de longitud, entre la serranía de Montecristo y el Abra de Chug-Chug (Figura 2). A partir de su primer reconocimiento pudimos comprobar que la mayor frecuencia y diversidad de evidencias se encontraban entre la Aguada de Chug-Chug y el sitio de geoglifos ChugChug Este-5, tramo sobre el que finalmente nos concentramos para realizar una prospección más intensiva, con un registro detallado de cada hallazgo sobre la vía. Para que se tenga una dimensión de 


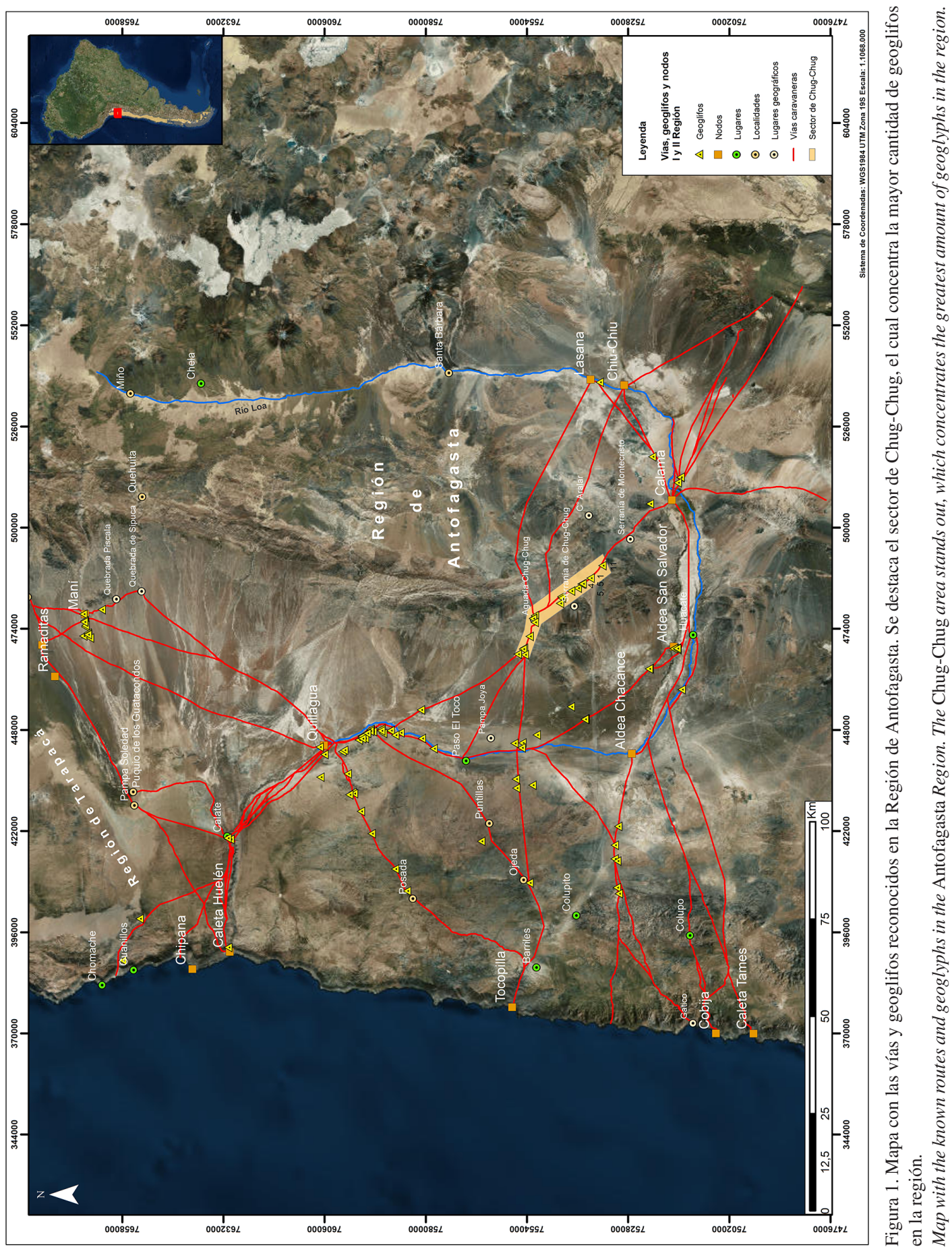




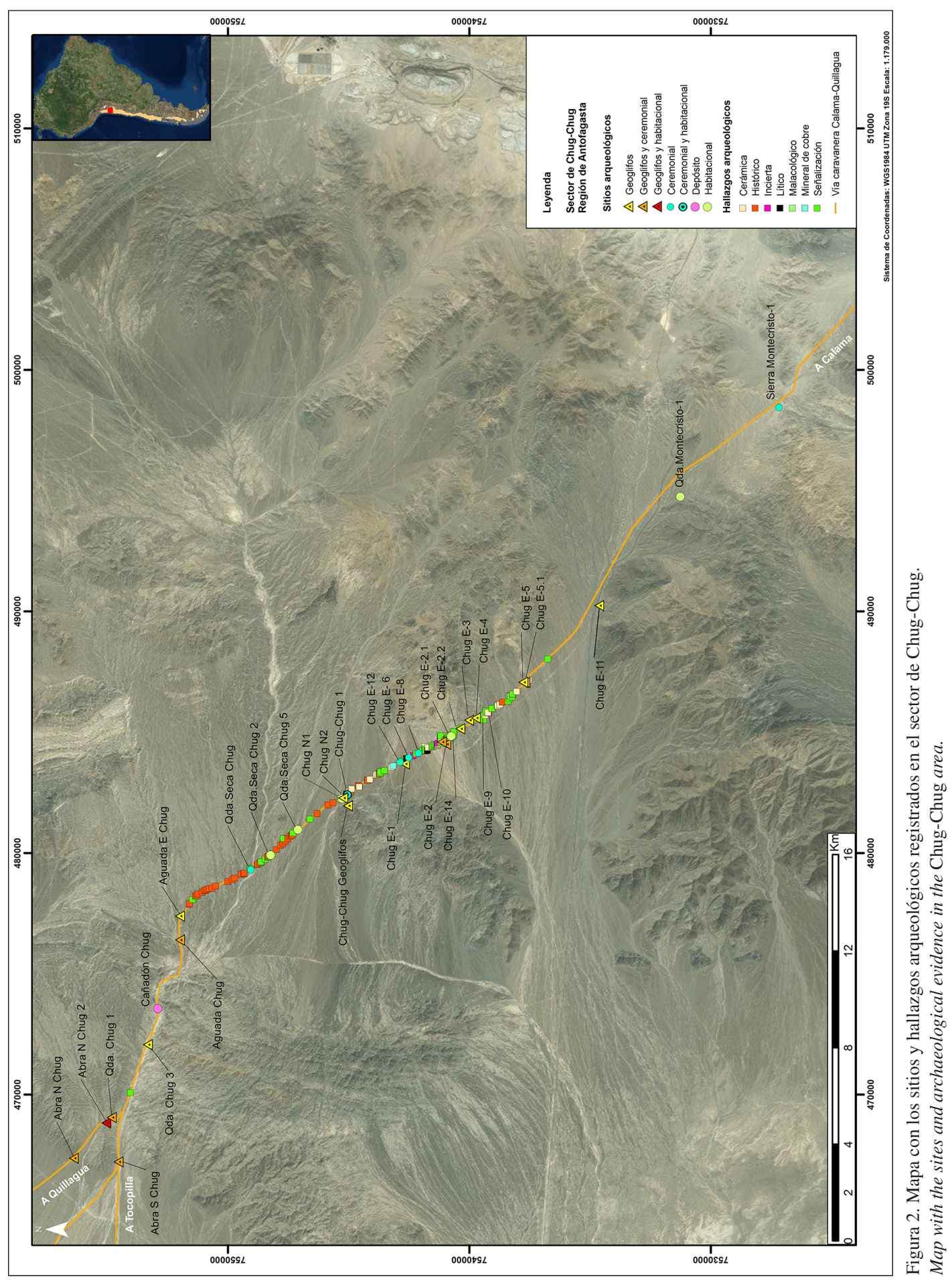


la densidad arqueológica del sector, en este último tramo -de $12 \mathrm{~km}$ - se identificaron 24 sitios y 167 puntos de hallazgos aislados, lo que se traduce en un promedio de $62 \mathrm{~m}$ entre evidencias arqueológicas de algún tipo. Si lo apreciamos por el número total de estructuras registradas en todo el tramo analizado $(n=339)$ y de las cuales 34 son estructuras simples de señalización, nos da un promedio de una estructura cada $113 \mathrm{~m}$. De los sitios prehispánicos (n=30), se reconocieron 18 sitios con geoglifos, le siguen en representación los sitios con carácter ceremonial, los sitios habitacionales y un caso que comparte tanto estructuras habitacionales como ceremoniales, además de un sitio de depósito o almacenamiento (collca). Analizamos estas evidencias según los principales tipos de contextos.

\section{Campamentos de descanso}

Las evidencias de estructuras de alojamiento $(n=39)$ se hallaron en siete sitios, aunque concentrándose la gran mayoría $(n=28)$ en solo dos sitios: Abra N Chug-Chug-2 y Quebrada Montecristo-1; indicando que ambos fueron los principales lugares de descanso en este segmento. Si consideramos además las estructuras habitacionales que están frente a los geoglifos de Chug-Chug (sitios Chug-Chug-1 y Chug-Chug Norte-2), podemos establecer así las tres principales paradas de los viajeros en el sector, mostrando una distancia bastante regular de $20 \mathrm{~km}$ entre éstos, lo que representa muy bien una jornada de viaje ${ }^{2}$. Son tipos de construcciones que destacan por su expeditividad, primando las plantas de formas tendientes a la circularidad (circular, semicircular u oval). La gran mayoría de los casos son simples depresiones de forma oval $(n=19)$ sin otros rasgos constructivos asociados, mientras que los restantes son de piedras y construidos a ras de piso. Hay otros tres que comparten además el espacio con geoglifos, dos de ellos ubicados frente al sitio principal de geoglifos de Chug-Chug (Tabla 1).

De los campamentos, se sondearon cinco estructuras procedentes de tres sitios (Chug-Chug-1, Quebrada Montecristo y Abra N Chug-Chug-2, con un total de 2,65 $\mathrm{m}^{2}$ excavados). Las evidencias recuperadas de los sondeos resultaron bastante mínimas (escasos desechos líticos, restos leñosos y fecas de camélido), mientras que los materiales diagnósticos registrados tanto en superficie como en estratigrafía corresponden a alfarería principalmente del período Intermedio Tardío (sitios Chug-Chug-1 y Quebrada Montecristo) y del componente Loa-San Pedro. También está representado más escasamente el componente tarapaqueño. Destacó el sitio Quebrada Montecristo-1, aquí se identificaron los tipos regionales Turi Rojo Alisado (TRA), Turi Gris Alisado (TGA), Turi Rojo Revestido (TRR) y Turi Rojo Pulido (TRP), además del componente tarapaqueño representado por un fragmento del

Tabla 1. Síntesis de los sitios con campamentos de alojamiento.

Summary of the camping sites.

\begin{tabular}{|c|c|c|c|c|c|c|c|}
\hline Código sitio & Tipo contexto & $\begin{array}{c}\mathrm{N}^{\circ} \\
\text { Estructuras }\end{array}$ & Camachico & Geoglifos & $\begin{array}{c}\text { Tipos } \\
\text { cerámicos }\end{array}$ & $\begin{array}{c}\text { Componentes } \\
\text { alfareros }\end{array}$ & $\begin{array}{l}\text { Cronología relativa } \\
\text { (período) }\end{array}$ \\
\hline Abra N Chug-Chug 2 & $\begin{array}{l}\text { Geoglifos y } \\
\text { habitacional }\end{array}$ & 16 & & Sí & & & Formativo? \\
\hline Qda. Seca Chug-Chug 2 & Habitacional & 1 & & No & & & Intermedio Tardío? \\
\hline Qda. Seca Chug-Chug 5 & Habitacional & 2 & & No & & & Intermedio Tardío? \\
\hline Chug-Chug 1 & $\begin{array}{c}\text { Habitacional } \\
\text { ceremonial y } \\
\text { geoglifos }\end{array}$ & 2 & $\mathrm{X}$ & Sí & $\begin{array}{l}\text { AIQ, TRA, } \\
\text { TRR, PCH }\end{array}$ & $\begin{array}{l}\text { Atacameño y } \\
\text { Tarapaqueño }\end{array}$ & Intermedio Tardío \\
\hline Chug-Chug Norte 2 & $\begin{array}{l}\text { Habitacional y } \\
\text { geoglifos }\end{array}$ & 5 & & Sí & $\begin{array}{l}\text { SEQ, AIQ, } \\
\text { TRA }\end{array}$ & Atacameño & $\begin{array}{l}\text { Formativo - Intermedio } \\
\text { Tardío // Histórico }\end{array}$ \\
\hline Chug-Chug Este 12 & Habitacional & 1 & & No & TRA & Atacameño & Intermedio Tardío \\
\hline Quebrada Montecristo 1 & Habitacional & 12 & & No & $\begin{array}{l}\text { TRA, TGA, } \\
\text { TRR, TRP y } \\
\text { PCZ }\end{array}$ & $\begin{array}{l}\text { Atacameño y } \\
\text { Tarapaqueño }\end{array}$ & Intermedio Tardío \\
\hline
\end{tabular}


tipo Pica Chiza (PCZ). Situación similar es la que muestra el sitio Chug-Chug-1 con los tipos Ayquina (AIQ), TRA y TRR del Loa-San Pedro y el tipo Pica Charcollo $(\mathrm{PCH})$ procedente del área tarapaqueña. En el sitio Chug-Chug Norte-2 se identificó el tipo Séquitor (SEQ) del Formativo Tardío y los tipos AIQ y TRA del período Intermedio Tardío atacameño. Un caso particular que también podría corresponder al período Formativo es el sitio Abra Norte Chug-Chug 2, el cual posee 16 depresiones ovales aglomeradas, excavándose una de ellas pero que no arrojó ningún material (Figura 3). En la superficie se registró una cuenta de mineral de cobre, un fragmento de ostión (Argopecten purpuratus) y escasos restos óseos de camélidos. Lamentablemente no contamos con materiales diagnósticos para inferir su cronología, pero este tipo de depresiones habitacionales aglomeradas las tenemos datadas desde el período Formativo en otros contextos similares en el sector de Calate (Pimentel et al. 2017).

En términos constructivos, los campamentos de descanso prehispánicos comparten un tipo de construcción muy simple y de baja inversión arquitectónica, sin importar el período que representan, siendo los recintos de formas tendientes a la circularidad una de las características indicativas de la continuidad de un patrón constructivo que se mantuvo en el tránsito internodal en todos los períodos preincaicos. Mientras en la arquitectura de los poblados hubo un importante cambio, como sucedió hacia tiempos tardíos con la entrada de un patrón más ortogonal, en los espacios de tránsito se mantuvieron los recintos circulares que provienen de la tradición arquitectónica de tiempos arcaicos.

\section{Estructuras ceremoniales}

Una situación bien distinta por su mayor densidad y variedad fue la que mostraron las estructuras ceremoniales. Se registraron 267 casos, distribuidos en 12 sitios y representando más del $84 \%$ de las estructuras, lo que da cuenta de la alta inversión involucrada en las prácticas ceremoniales viajeras en este tramo. Chug-Chug, en efecto, nos muestra no solo una alta densidad de rasgos ceremoniales, sino también la mayor diversidad que reconocemos en la región. De acuerdo a sus características formales y determinados materiales diagnósticos, distinguimos cinco tipos de estructuras que remiten a prácticas ceremoniales particulares: Camachico, Oquedades
Artificiales, Muros y Cajas, Líneas de Piedras y "amontonamientos menores sobre cerros" (Tabla 2). Muestra también una situación singular al concentrar distintos tipos de estructuras ceremoniales en un mismo sitio, las que en otros contextos viales de la región aparecen notablemente diferenciados (Pimentel 2009). Es el caso de Abra Norte Chug-Chug, sitio que concentra casi toda la diversidad de estructuras (4/5), Sierra de Montecristo-1 y Chug-Chug Este 5, que comparten estructuras del tipo Muros y Cajas y Camachico, o los sitios Quebrada Seca ChugChug y Chug-Chug Este 6 que comparten los tipos Camachico y Oquedades Artificiales.

\section{Amontonamientos menores sobre cerros}

Los rasgos más simples y comunes son los "amontonamientos menores sobre cerros" ( $n=132)$, los cuales corresponden a estructuras de piedras de pequeñas dimensiones y emplazados en la parte alta de los cerros. En Chug-Chug se registraron en cinco sitios, todos asociados con geoglifos. Aquí los materiales fueron escasos, identificándose en algunos casos mineral de cobre triturado, líticos, algunos fragmentos cerámicos y cuentas.

\section{Camachico}

Con Camachico nos referimos a un tipo de estructura monticular que se suele confundir con las clásicas apachetas, pero que se distinguen formalmente por su bajo tamaño, diferenciándose de las clásicas estructuras piramidales altamente visibles que suelen encontrarse sobre los $4.000 \mathrm{msm}$. El término Camachico es tomado de la descripción que hace el párroco Albornoz cuando describe el ritual de la apacheta que llaman "apachita o camachico por otro nombre"; especialmente cuando le agrega singularidad en su descripción al señalar que: "otros escarvan la tierra en la propia guaca y, escarvándola, cuentan sus travajos o prosperidades a dicha guaca" (Albornoz 1989 [ca. 1582]:168). Este gesto ritual nos retrotrae justamente a aquellos rasgos arqueológicos que encontramos como parte del acto ceremonial que es la excavación de oquedades al interior del montículo. No sería de extrañar que Camachico corresponda en realidad a otro tipo ritual que el párroco haya simplemente asimilado con las apachetas, puesto que siendo posiblemente de origen aymara es apachita el término para referirse a las apachetas en dicha lengua. De esta manera, con esta 


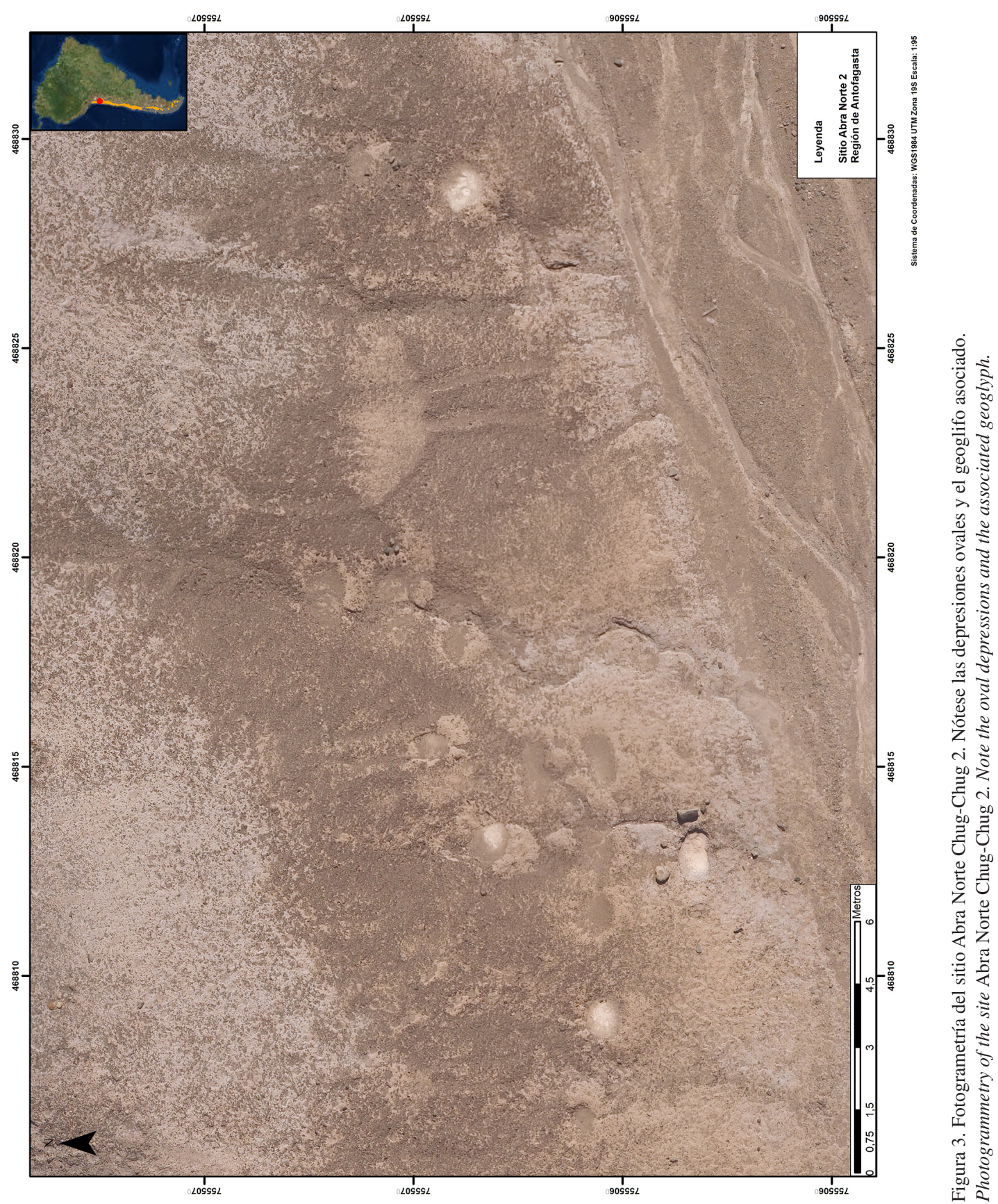




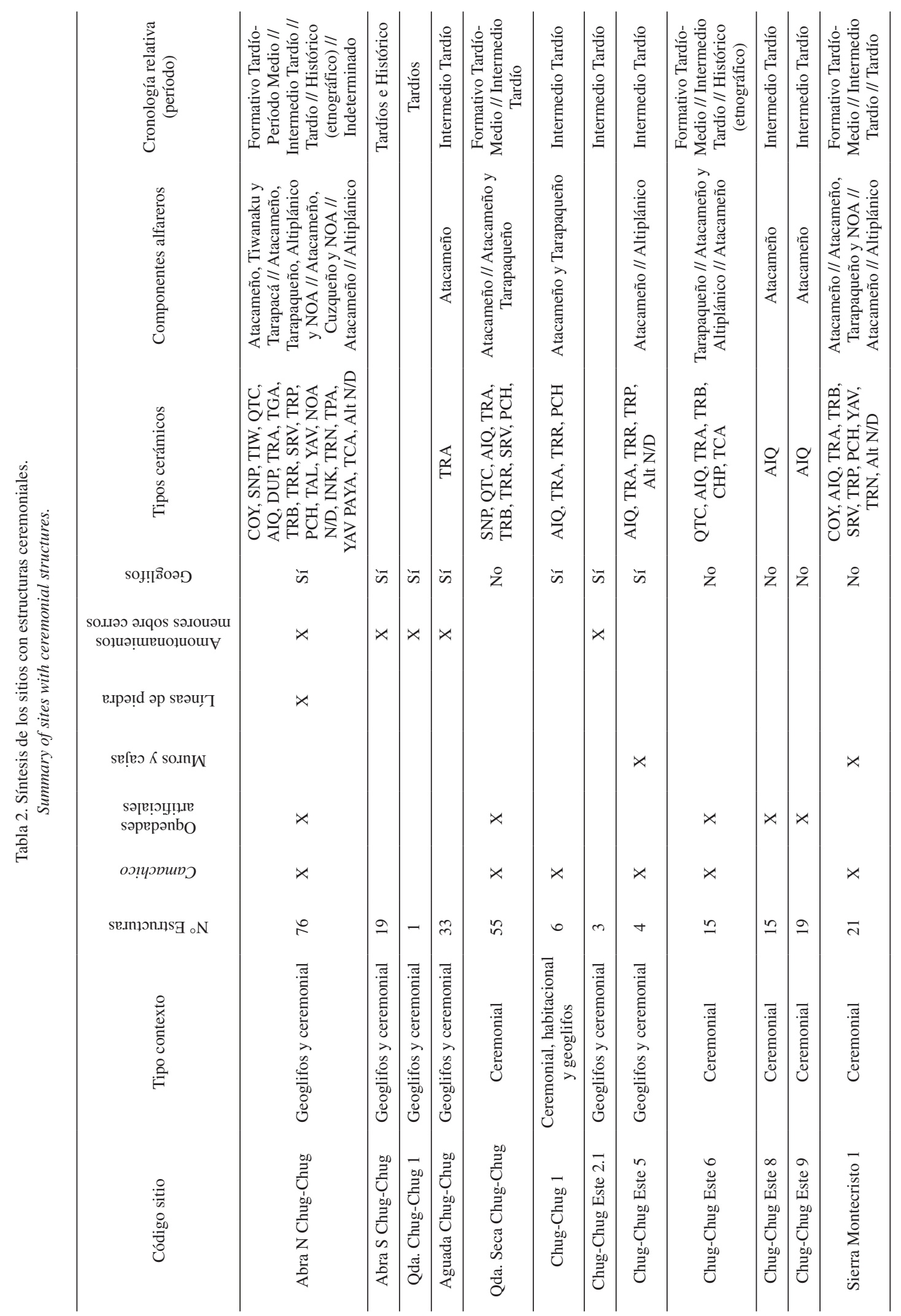


ambigüedad histórica es que nos apropiamos del término camachico $^{3}$ para nominar a estas nuevas evidencias rituales que son claramente distintas de las apachetas (Pimentel 2013).

Este tipo de estructura ceremonial fue la que mostró la mayor complejidad y un intenso depósito cultural, identificándose seis casos en Chug-Chug, la mayor concentración que hemos reconocido. Nos concentramos particularmente en la estructura Camachico del sitio Abra Norte Chug-Chug, ya que contamos con intervenciones estratigráficas, análisis de los materiales y dataciones absolutas.

\section{Sitio Abra Norte Chug-Chug}

El sitio está compuesto por una gran cantidad de estructuras $(n=76)$, entre las cuales se reconocen Oquedades Artificiales, "amontonamientos menores sobre los cerros", Líneas de Piedras, además de 17 motivos de geoglifos (Figura 4). El único caso de Camachico aquí es la estructura 1, que se emplaza en la entrada al abra desde el poniente, en su borde norte. Corresponde a un montículo de planta subcircular, de $3,30 \mathrm{~m}$ por $2,60 \mathrm{~m}$ y una altura de $40 \mathrm{~cm}$ (Figura 5), que presentaba una oquedad central de $40 \mathrm{~cm}$ de diámetro y 20 $\mathrm{cm}$ de profundidad; la estructura fue construida por la acumulación sucesiva de clastos en torno al montículo y la oquedad central. Junto a las piedras de origen local, también se hallaron algunos clastos alóctonos, especialmente trasladados de otras áreas para ser incorporados dentro de la estructura. Se excavaron cuatro unidades $\left(2,25 \mathrm{~m}^{2}\right)$ que se distribuyeron alrededor de la oquedad central, permitiendo identificar tres capas estratigráficas. En la capa 1 se registró una oquedad en el piso original del sitio y cubierta con clastos, donde se depositó una importante concentración de materiales (Rasgo 1). Cabe destacar la presencia de fecas de equino, dando cuenta de su reutilización hasta tiempos históricos. Dentro de la capa 2 se identificó otro rasgo que concentraba materiales vegetales, mineral de cobre triturado y desechos líticos principalmente.

Tal como se aprecia en la Tabla 3, hay una alta diversidad de materiales, predominando los vegetales como carpos y palitos de algarrobo, brea, carozo de chañar, calabaza y mazorca, chalas y grano de maíz. Hay restos de roedores, fecas de camélido y mineral de cobre, tanto en fragmentos como en cuentas. Hay desechos de talla lítica, vasijas cerámicas, plumas, placas de oro y cobre. En frecuencias menores se registran restos óseos de pescado, hematita, vellones, cordelería, palitos embarrilados, conchas, una figurilla femenina de piedra, un fragmento de textil, un fragmento de placa lítica y piedra roja triturada (Tabla 3 ). De acuerdo a cada capa reconocida, la cantidad y variabilidad de los materiales se incrementan notablemente hacia la base del depósito, disminuyendo su intensidad en las capas superiores (Tabla 4). Se obtuvo una datación por AMS provenientes de la concentración vegetal del rasgo 1 de la capa 2, obteniéndose como resultado un rango de fechas entre el 1185 d.C. y el 1275 d.C., lo que lo asigna a la mitad del período Intermedio Tardío (Tabla 5). Los análisis cerámicos (Correa y García 2014) identificaron principalmente un componente atacameño del período Intermedio Tardío e Inca, representado mayormente por vasijas restringidas de los tipos TRA, TGA, TRR, y en menor medida por fragmentos Ayquina (AIQ) y Dupont (DUP), junto con tipos inca local (TRN) y etnográfico (TCA). De la alfarería foránea hay presencia del componente tarapaqueño con los tipos QTC y PCH, y del Río Grande de San Juan, en la frontera entre Jujuy y sur Bolivia, con los tipos Yavi (YAV), incluyendo un fragmento de aríbalo decorado Yavi La Paya de data incaica y un fragmento inca (INK) de factura imperial. A todo esto se agrega el singular registro de un fragmento de kero Tiwanaku en las inmediaciones de la estructura.

De los análisis de las cuentas (Soto 2011) se observó que la gran mayoría corresponde a cuentas discoidales mínimas y pequeñas $(<6 \mathrm{~mm})$, encontrándose principalmente enteras y algunos casos de fragmentos. Se pudo reconocer una importante variedad de materias primas entre las que destacan la crisocola, seguido de malaquita, turquesa y mineral de cobre, identificándose en frecuencias menores cuentas de ignimbrita, lítico y concha (Tabla 5). De esto último es relevante la identificación de cuatro ejemplares de Spondylus sp., que, como se sabe, es un tipo de molusco que procede de aguas cálidas (litoral de Ecuador y Perú) y que en la región atacameña se había hallado únicamente en contextos incaicos, por lo que resulta muy significativa su presencia en el contexto de Chug-Chug.

Se trata así en definitiva de una práctica ceremonial particular que tuvo su mayor intensidad en el período Intermedio Tardío, para continuar posteriormente en tiempos incaicos y coloniales. 


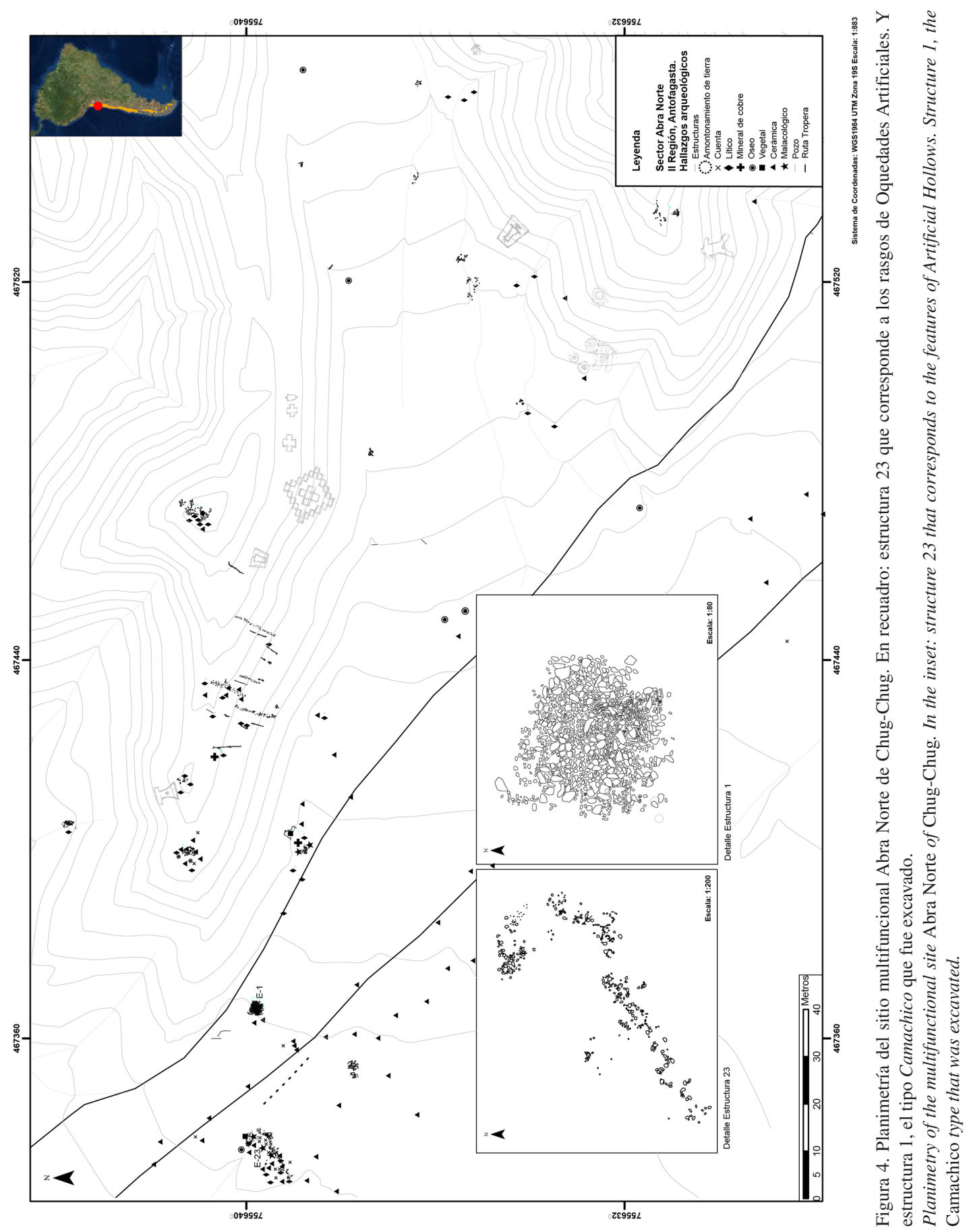



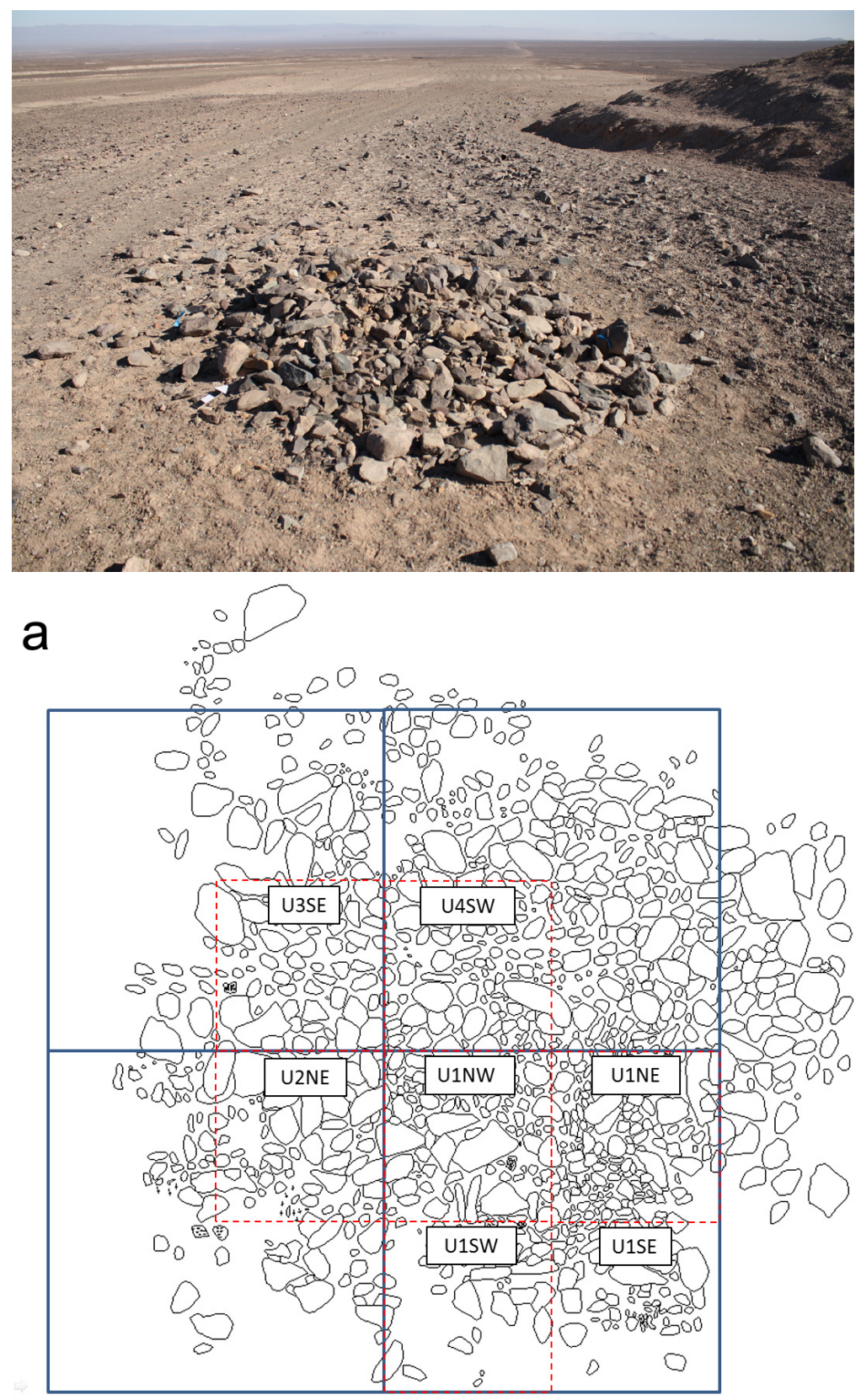

b

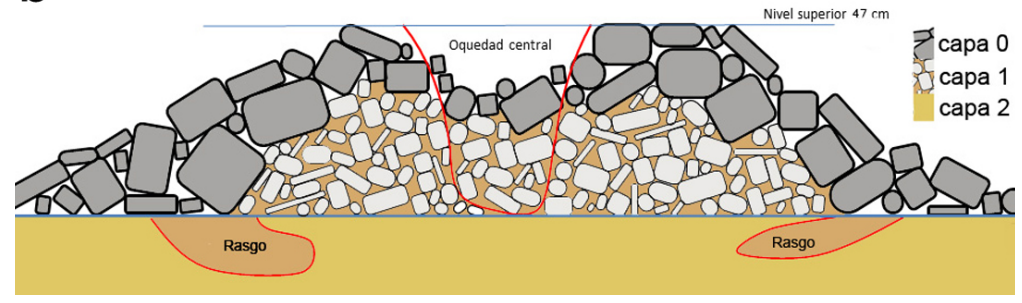

Figura 5. Estructura tipo Camachico, sitio Abra Norte de Chug-Chug, con dibujo de planta y de sección.

Camachico-type structure, site Abra Norte of Chug-Chug, With drawing of plant and section. 
Tabla 3. Distribución de materiales según capas excavadas en la Estructura 1 (Camachico), sitio Abra Norte Chug-Chug. Distribution of materials according to the excavated layers in Structure 1 (Camachico), Abra Norte Chug-Chug Site.

\begin{tabular}{|c|c|c|c|c|c|}
\hline \multirow{2}{*}{ Material } & \multicolumn{5}{|c|}{ Capa } \\
\hline & Sup. & 1 & 2 & Total & $\%$ \\
\hline Carpo Algarrobo & & 70 & 553 & 623 & 19,0 \\
\hline Carozo Chañar & & 15 & 35 & 50 & 1,5 \\
\hline Mazorca Maíz & & 1 & 7 & 8 & 0,2 \\
\hline Grano de Maíz & & & 3 & 3 & 0,1 \\
\hline Calabaza & & 1 & 3 & 4 & 0,1 \\
\hline Ramas y palitos & & 389 & 359 & 748 & 22,8 \\
\hline Palos embarrilados & & 6 & & 6 & 0,2 \\
\hline $\begin{array}{c}\text { Partículas de mineral } \\
\text { de cobre }\end{array}$ & 10 & 258 & 641 & 909 & 27,7 \\
\hline Desechos líticos & 22 & 266 & 93 & 381 & 11,6 \\
\hline Cerámica & 5 & 109 & 62 & 176 & 5,4 \\
\hline Cuentas & 1 & 33 & 53 & 87 & 2,7 \\
\hline Plaquitas de Oro & & 10 & 24 & 34 & 1,0 \\
\hline Plaquitas de plata & & 1 & 1 & 2 & 0,1 \\
\hline Placa lítica & & 1 & & 1 & 0,0 \\
\hline Figurilla de piedra & & 1 & & 1 & 0,0 \\
\hline Hematita & & 10 & 8 & 18 & 0,5 \\
\hline Mortero & 1 & & & 1 & 0,0 \\
\hline $\begin{array}{c}\text { Trituramiento de } \\
\text { piedra roja }\end{array}$ & & 4 & & 4 & 0,1 \\
\hline Óseo mamífero & 15 & 4 & 12 & 31 & 0,9 \\
\hline Ictiológico & & 10 & 12 & 22 & 0,7 \\
\hline Concha & & 1 & 1 & 2 & 0,1 \\
\hline Textil & & 1 & & 1 & 0,0 \\
\hline Vellones & 1 & 11 & 5 & 17 & 0,5 \\
\hline Cordelería & & 9 & 4 & 13 & 0,4 \\
\hline Plumas & & 29 & 33 & 62 & 1,9 \\
\hline Fecas de equino & & 7 & & 7 & 0,2 \\
\hline Fecas de camélido & & 1 & 5 & 6 & 0,2 \\
\hline Feca no identificada & & 9 & 15 & 24 & 0,7 \\
\hline Vidrio & 18 & 25 & 1 & 44 & 1,3 \\
\hline Total & 73 & 1.282 & 1.930 & 3.285 & 100,00 \\
\hline$\%$ & 2,22 & 39,03 & 58,75 & 100,00 & \\
\hline
\end{tabular}

\section{Oquedades Artificiales}

Las Oquedades Artificiales corresponden a un tipo de ritual que consistió en la excavación de oquedades en la superficie para depositar ofrendas y libaciones. Son conocidas etnográficamente en el altiplano boliviano como "sepulcros" (Nielsen 1997), siendo identificados en los puntos altos de las rutas asociados a abras o portezuelos y con una extensa distribución geográfica que incluyó el noroeste argentino, altiplano de Lípez y norte de Chile (Nielsen 2006; Pimentel 2009). En el caso de Chug-Chug, la característica principal es que se encuentran alineadas en un eje transversal a la vía y emplazadas en sectores de planicies. Poseen forma subcircular o circular y a su alrededor se ofrendaron una importante variedad de bienes, principalmente pequeños fragmentos de mineral de cobre triturado y cuentas de ignimbrita. Se registraron en cinco sitios y en tres de ellos se encuentran compartiendo espacio con estructuras del tipo Camachico.

Aquí destacó el sitio Quebrada Seca Chug-Chug, del cual se obtuvo una datación procedente de la capa 2 por AMS que lo asignó a la etapa final del período Intermedio Tardío, entre el 1205 d.C. y el 1375 d.C., un rango de fechas muy coincidente con la obtenida del camachico (Tabla 5). Se hallaron diversos materiales como pequeñas partículas de mineral de cobre, cuentas discoidales, fragmentos cerámicos, restos malacológicos y leñosos. De los fragmentos cerámicos predominó el componente Loa-San Pedro del período Intermedio Tardío (TRA, AIQ, y SRV, TRR), y se reconoció además un componente tarapaqueño, aunque muy escaso, del Período Formativo (QTC) y del período Intermedio Tardío (PCH) (Correa y García 2014). Sin duda, es otro tipo de práctica ceremonial que fue característica de los viajeros del período Intermedio Tardío y por lo tanto contemporánea a los Camachico (Figura 6).

\section{Muros y Cajas}

Los Muros y Cajas son el tipo de sitio ceremonial mejor investigado en el área atacameña, siendo reconocido inicialmente por Pollard (1970) en el Loa Medio y en la cuenca alta del río Salado, a lo que se suman los trabajos posteriores en Chiu-Chiu (Thomas 1978) y en el Alto Loa (Berenguer 1994, 1995, 2004; Sinclaire 1994). Se caracteriza por la presencia de muros rectos o levemente curvos, a los que se le asocian numerosas pequeñas estructuras 


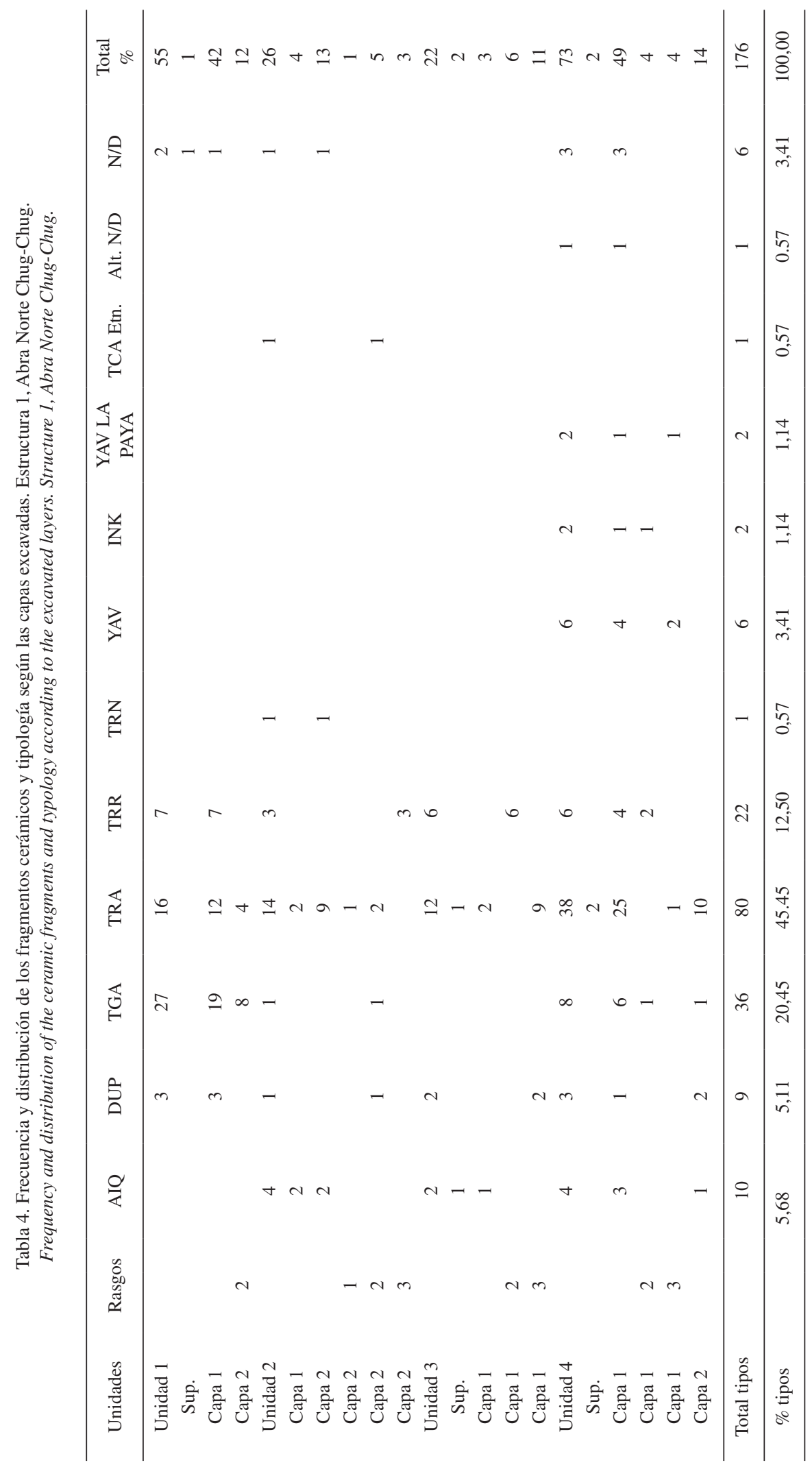


Tabla 5. Dataciones calibradas obtenidas de los sitios Abra Norte Chug-Chug (E1) y Sepulcro Chug-Chug (E16). Dataciones calibradas usando la curva SHCAL13 en el programa Calib 7.1 (Stuiver et al. 2017). Calibrated dates of the Abra Norte Chug-Chug Site (Structure 1) and Sepulcro Chug-Chug site. All dates were calibrated with curve SHCAL13 and Calib 7.1 program (Stuiver et al. 2017).

\begin{tabular}{cccccc}
\hline Sitio & Unidad & Código laboratorio & Material & Años ${ }^{14}$ C a.p. & Cal 2 $\delta(95,4 \%)$ \\
\hline Abra Norte Chug-Chug & E1 U2 C2 & Beta 295678 & madera & $850+30$ & $1185-1275$ d.C. \\
Sepulcro Chug-Chug & E16 U1 C2 & Beta 275739 & carpo algarrobo & $800+40$ & $1205-1300$ d.C. 1365-1375 d.C. \\
\hline
\end{tabular}

rectangulares construidas con lajas dispuestas verticalmente, de lo cual deriva el término "cajas". Si bien se encuentran sitios de cajas solas o muros sin cajas, lo más común es la relación entre ambos tipos de estructuras. En Chug-Chug identificamos dos sitios con muros y cajas y uno con una "cajita" aislada, los que comparten el sitio con estructuras del tipo Camachico. Estas corresponden a las evidencias más occidentales reconocidas hasta ahora para este tipo de sitio. En el sitio Abra Norte Chug-Chug se identificó una "cajita" aislada que se encuentra en la parte alta de un cerro y otra en el sitio Sierra de Montecristo-1 en asociación con otras evidencias ceremoniales en un sector de planicie con alta visibilidad del entorno (Figura 7). En ambos casos se trata de pequeñas estructuras de forma rectangular construidas con lajas dispuestas de canto, con mínimos materiales, como mineral de cobre triturado; destacó el sitio Sierra de Montecristo-1 con una importante variedad de tipos cerámicos, tanto del componente local Loa-San Pedro (COY, AIQ, TRA, TRB, SRV, TRP), como de la tradición tarapaqueña (PCH), del río Grande de San Juan, sur de Bolivia (YAV) y del altiplano (Alt. N/D).

\section{Lineas de Piedras}

Estructuras del tipo Líneas de Piedras las identificamos únicamente en el sitio Abra Norte Chug-Chug, tratándose de múltiples líneas dispuestas a ras de piso sobre la ladera de un pequeño lomaje $(\mathrm{n}=28)$, las que fueron construidas en una sola hilera de piedras y de trazado recto o levemente curvo. No se registraron materiales asociados, pero este tipo de rasgos lo hemos reconocido profusamente en la Depresión Intermedia y muchas veces en asociación a tumbas del período Formativo de viajeros de origen costero (Pimentel 2009; Pimentel y Ugarte 2016; Torres-Rouff et al. 2012). Que en el sector de ChugChug se encuentren solo en el Abra Norte, un abra que por lo demás marca el paso entre la Cordillera del Medio y la Depresión Intermedia, nos refuerza la idea de que estas manifestaciones debieron ser producidas por grupos costeros, marcando este sitio el límite altitudinal de estas evidencias.

En definitiva, estructuras como Camachico, Muros y Cajas y Oquedades Artificiales son manifestaciones propias de los viajeros caravaneros que transitaron en la región en el período Intermedio Tardío (Berenguer 1994, 2004; Nielsen 1997; Pimentel 2009), mientras que las Líneas de Piedras las asociamos a grupos costeros del período Formativo. El tipo Camachico por ahora no se registra en tierras altas, siendo más bien característico de la Depresión Intermedia y la Cordillera del Medio, y entre las regiones de Tarapacá y Atacama. Las Oquedades Artificiales se encuentran en todo el perfil altitudinal en ambas vertientes de la cordillera de los Andes, por lo que fue una práctica transversal a los viajeros de la Circumpuna. Los Muros y Cajas, por su parte, se restringen principalmente a las localidades de ChiuChiu, Lasana y Alto Salado, con lo cual da cuenta de manifestaciones más locales. Los Camachico destacan por presentar una alta diversidad de bienes que en su conjunto son representativos de todos los pisos ecológicos, desde el Pacífico hasta la ceja de selva, e incluye buena parte de los elementos de la naturaleza. Así, están representados elementos del mundo vegetal (algarrobo, chañar, maíz, calabaza, restos leñosos), fauna terrestre (restos de camélido, vellones, fecas de camélido), fauna marina (moluscos, pescados), aves (plumas de pelícano y loro) minerales (cobre) y materias primas aptas para la talla lítica. A todo esto se agregan bienes manufacturados como alfarería, cuentas discoidales, placas de cobre, plata y oro, además de cordelería y textiles (Pimentel 2009, 2013). Si algo se resalta en este acto ritual es que la importancia está en la presencia y la mayor variabilidad de los bienes, y no en la cantidad o el tamaño de un determinado bien, como si su sola 


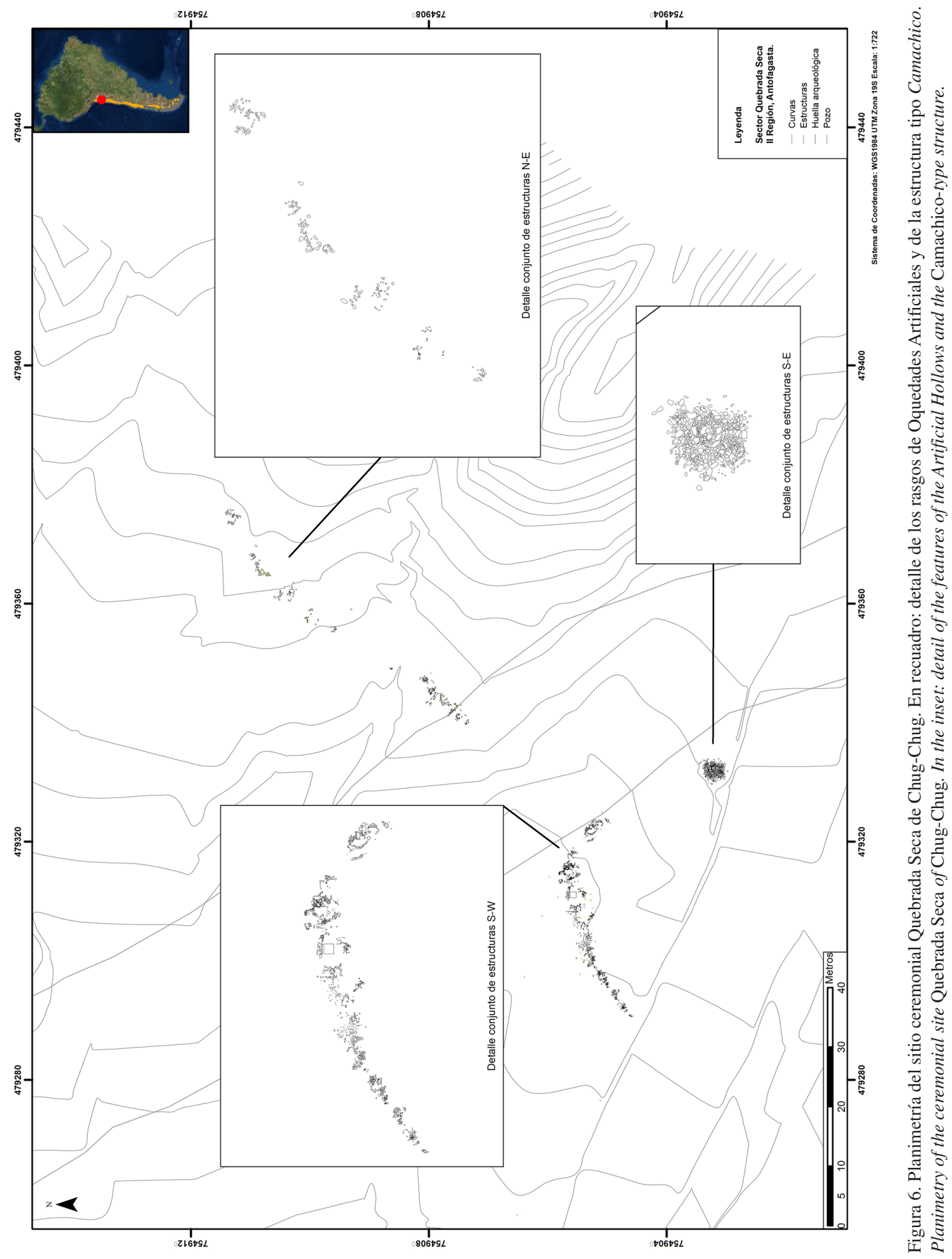




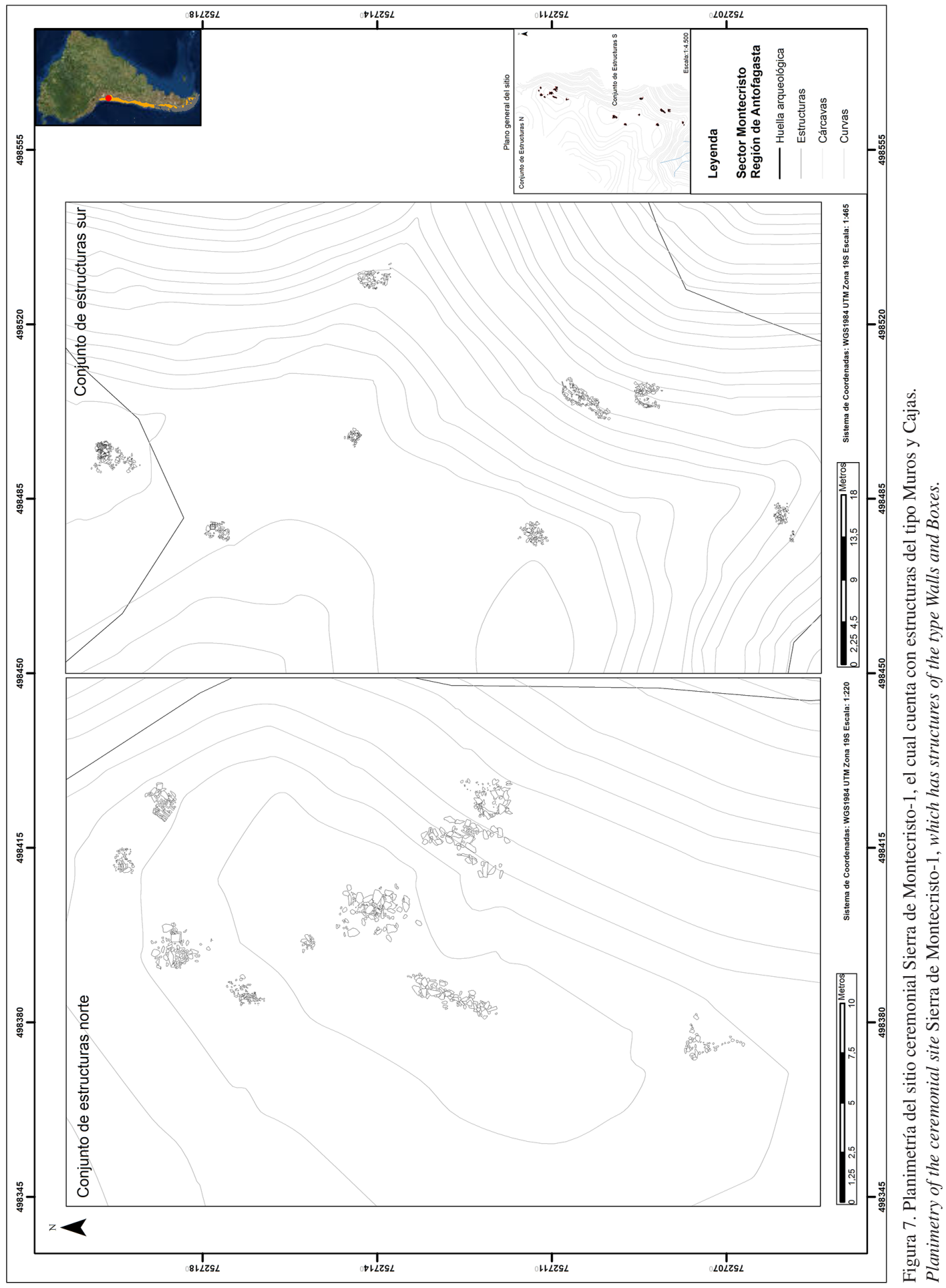


presencia conectara el espacio ritualizado con toda la amplitud de la red del tráfico macrorregional. Con la ofrenda el desierto no solo es objeto de ceremonias, sino que es también altamente representativo del sistema de intercambio económico social.

\section{Los Geoglifos de Chug-Chug}

Una característica propia de este tipo de representaciones es su monumentalidad, exageración visual y alta visibilidad, lo que permite que puedan ser vistos normalmente a grandes distancias. Chug-Chug concentra la mayor frecuencia de estas manifestaciones en toda la región, con 18 sitios y 560 motivos (Tabla 6). La mayoría de las figuras se encuentran dispuestas en las laderas de los cerros, aunque hay tres que se ubicaron en superficies planas. Nueve son sitios exclusivos de geoglifos, mientras que seis están asociados a estructuras de carácter ceremonial, dos a estructuras habitacionales y uno a ambos tipos de estructuras. La mayor concentración se encuentra en el conocido sitio de Chug-Chug Geoglifos ( $\mathrm{n}=402$ motivos), seguido bastante más abajo por los sitios Chug-Chug Este $1(\mathrm{n}=57)$, ChugChug Este $4(n=26)$, Aguada Chug-Chug $(n=24)$ y Abra Norte Chug-Chug $(\mathrm{n}=17)$. Todos los demás poseen menos de 10 motivos (Figuras 8 a la 13).

Cronológicamente, los geoglifos fueron realizados mayoritariamente en el período Intermedio Tardío, época en la cual se estandarizaron las figuras humanas con personajes representados de frente, sin animación y ataviados con túnicas y tocados, mientras los camélidos se volvieron cada vez más simplificados, con trazos lineales y rectilíneos. Pero Chug-Chug también da cuenta de una secuencia más amplia que podemos retrotraer por lo menos al período Formativo. Elementos como "cabezas radiadas", los que se encuentran representados en cestos del cementerio de Topater del Formativo Medio, camélidos de formas naturalistas y antropomorfos simples y con gestos de animación, son los principales referentes para ampliar su cronología hasta el 1000 a.C. y con una continuidad hasta los períodos tardíos.

El 62\% de los motivos de geoglifos corresponden a figuras geométricas $(\mathrm{n}=347), 18,2 \%$ a antropomorfos $(n=102)$ y $13,7 \%$ a representaciones zoomorfas $(n=77)$. Las dimensiones de los motivos varían entre 0,5 a $24 \mathrm{~m}$ de largo, con un promedio de 5,3 $\mathrm{m}$. La mayoría fueron realizados preferentemente mediante la técnica de sustracción ( $\mathrm{n}=416)$, aunque la técnica aditiva está bien representada $(n=128)$, siendo bastante menores los casos en se ocuparon balanceadamente ambas técnicas $(n=14)$. Por otra parte, hay una preponderancia por la ocupación de un trazado areal $(n=445)$, vale decir, de aquellas figuras que se realizaron mediante despejes de áreas geométricas a diferencia de los trazos lineales que se ocupan normalmente para hacer los contornos de las figuras, observándose una cantidad notoriamente menor de los trazos lineales $(\mathrm{n}=68)$ y mixtos $(\mathrm{n}=45)$, los que están por debajo del $10 \%$.

De las figuras geométricas, tienen frecuencias similares los motivos compuestos $(n=176)$ como rombos escalerados y círculos concéntricos, y los simples $(\mathrm{n}=169)$, como rectángulos. Entre los motivos zoomorfos lo más frecuente son los camélidos ( $\mathrm{n}=34)$, seguido de las aves $(\mathrm{n}=12$, entre ellas el suri), lagartos $(n=10)$, tres felinos, tres anfibios, dos cánidos y una especie de pescado, la albacora (Xiphias gladius). En su conjunto la fauna es representativa de los distintos pisos ecológicos por los que circulaban los caravaneros en sus viajes, desde la costa hasta la Puna y el Altiplano. Los camélidos fueron los que mostraron una mayor variación estilística, desde modalidades más propiamente naturalistas del período Formativo, hasta trazos más rectilíneos y característicos de los períodos tardíos (p.ej. Berenguer 1999, 2004; Berenguer et al. 1985; Gallardo et al. 1999, 2012).

Esta variabilidad estilística se hace más compleja en la construcción de las figuras antropomorfas, donde se observó desde representaciones de figuras humanas simples ( $\mathrm{n}=24)$, hasta figuras de gran complejidad $(\mathrm{n}=78)$, ataviadas con túnicas y tocados, portando varas o báculos, hachas, escudos y lanzas, en acto de pesca o el caso de la imagen icónica del sacrificador con un hacha y una cabeza cercenada en una de sus manos. Se representaron preferentemente en posición rígida y de frente $(n=67)$, las menos de perfil $(n=2)$ e incluso combinando ambas soluciones $(\mathrm{n}=8)$ para aquellos casos en que se quiso destacar gestos de movimiento o animación en las extremidades inferiores, mientras el tronco fue representado de frente. Las figuras humanas muestran un particular manejo de las proporciones del cuerpo que consistió en la exagerada desproporción de determinados rasgos anatómicos como la cabeza y el cuello, junto a una reducción de las extremidades inferiores. Otra tendencia reconocida fue la amplificación de la representación de la vestimenta (túnica), seguramente con el fin de otorgarle mayor connotación y 


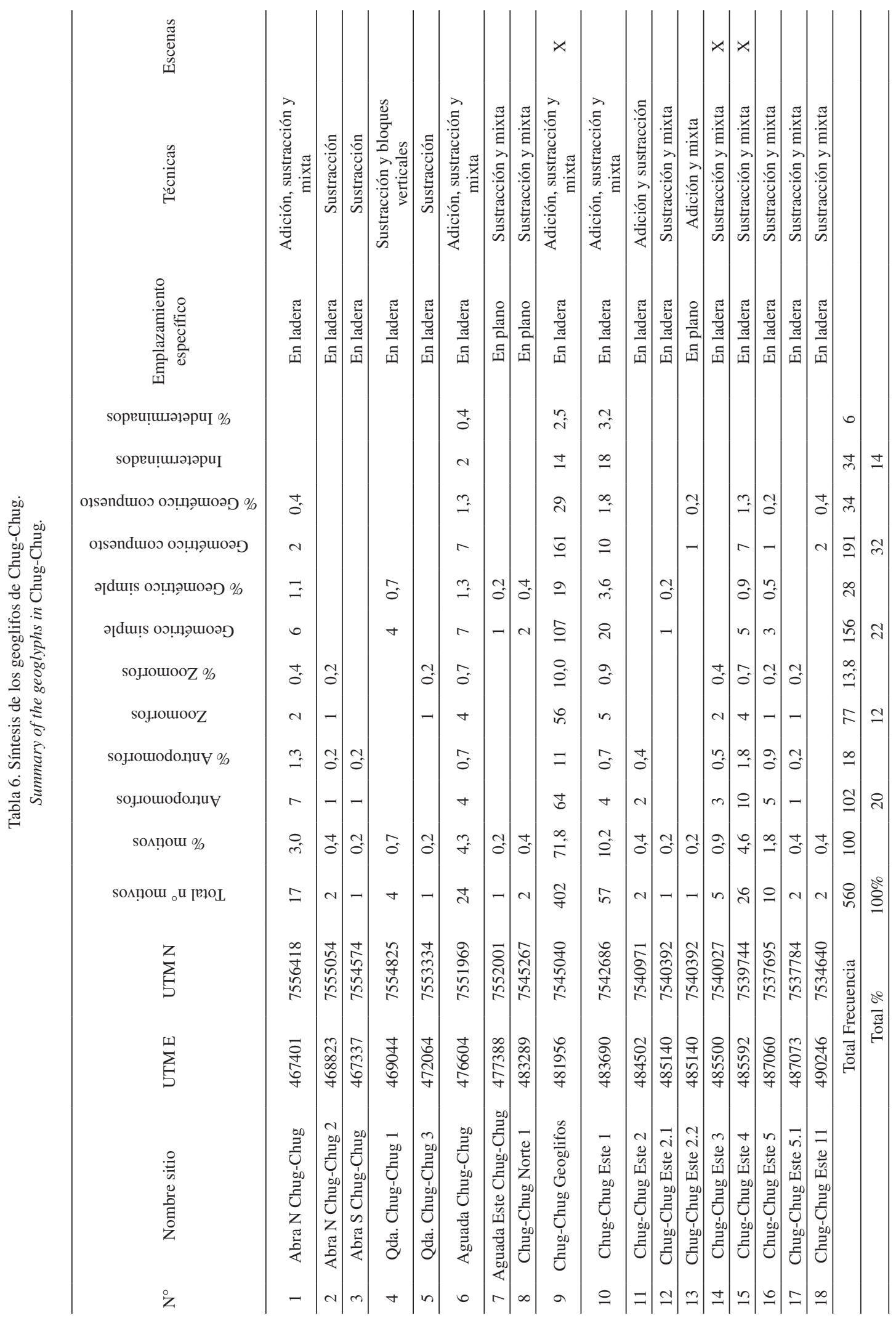




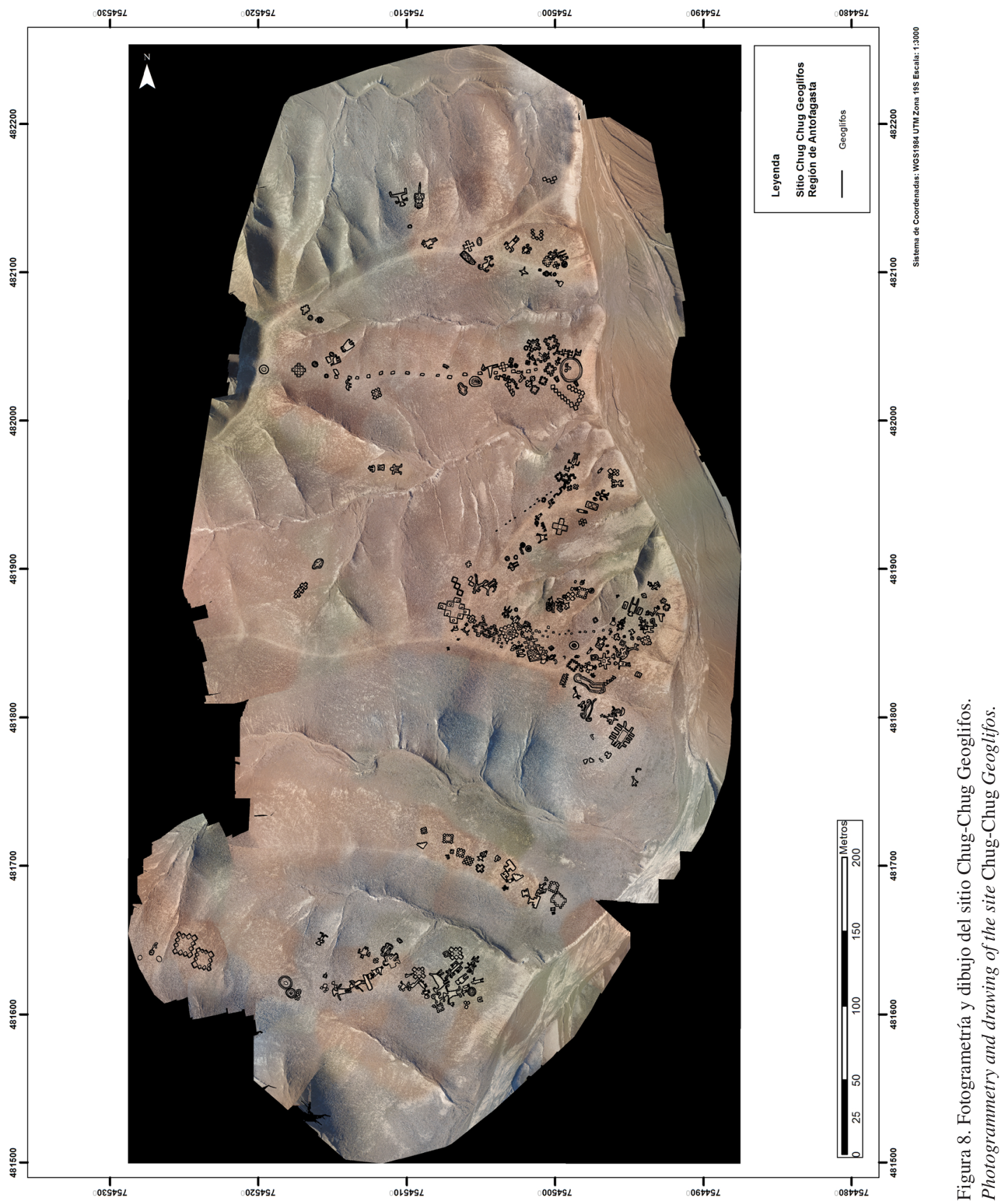




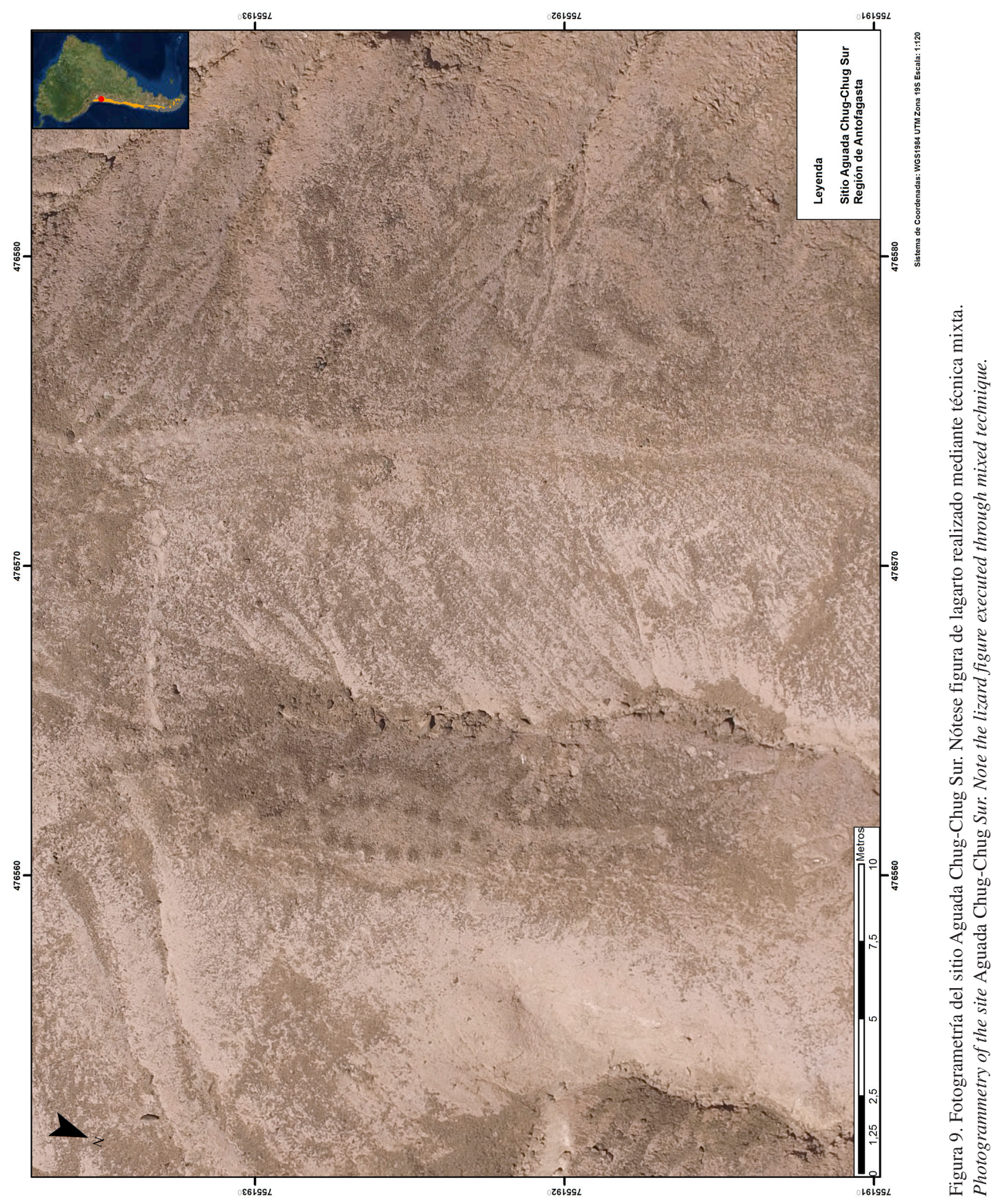




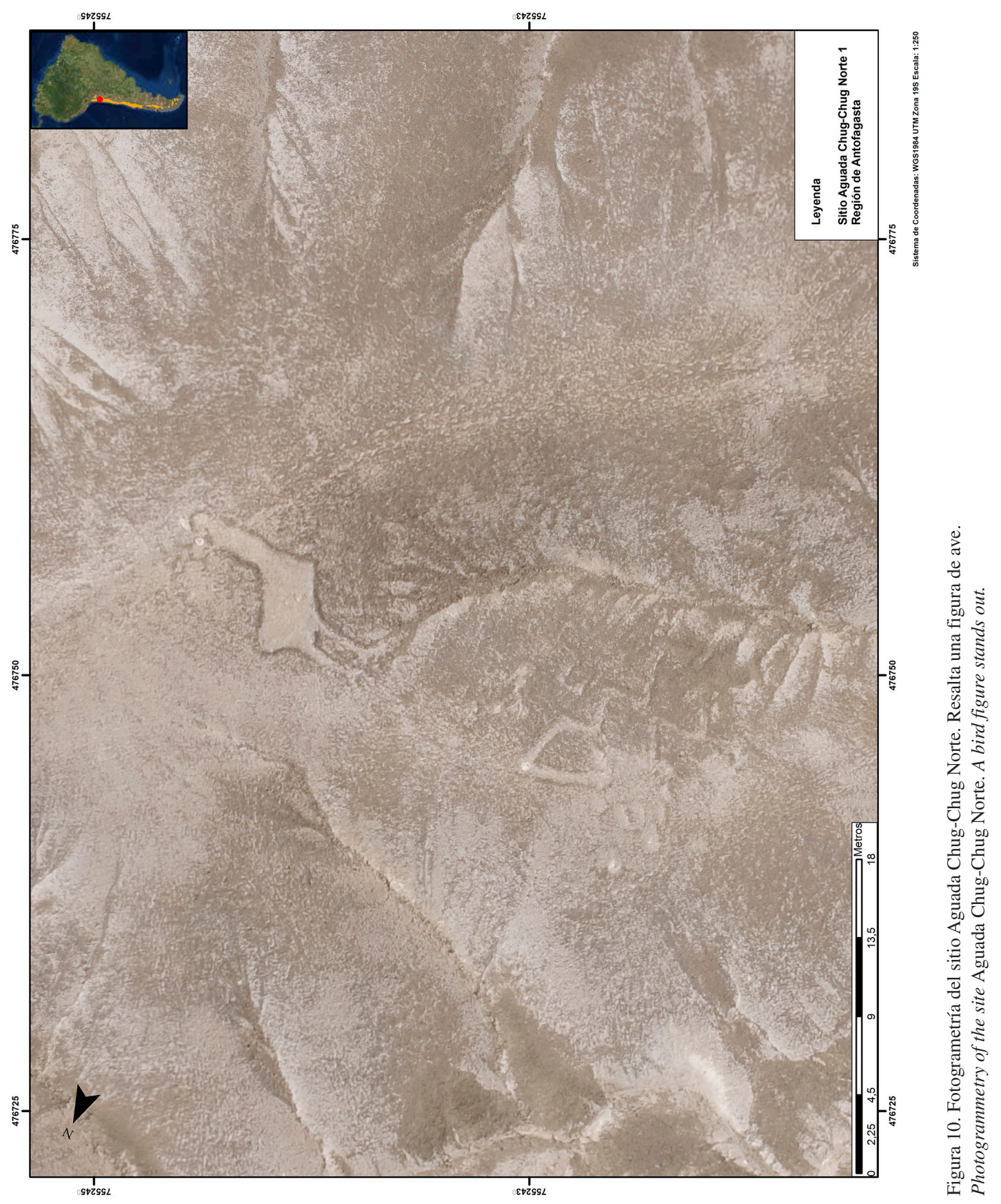




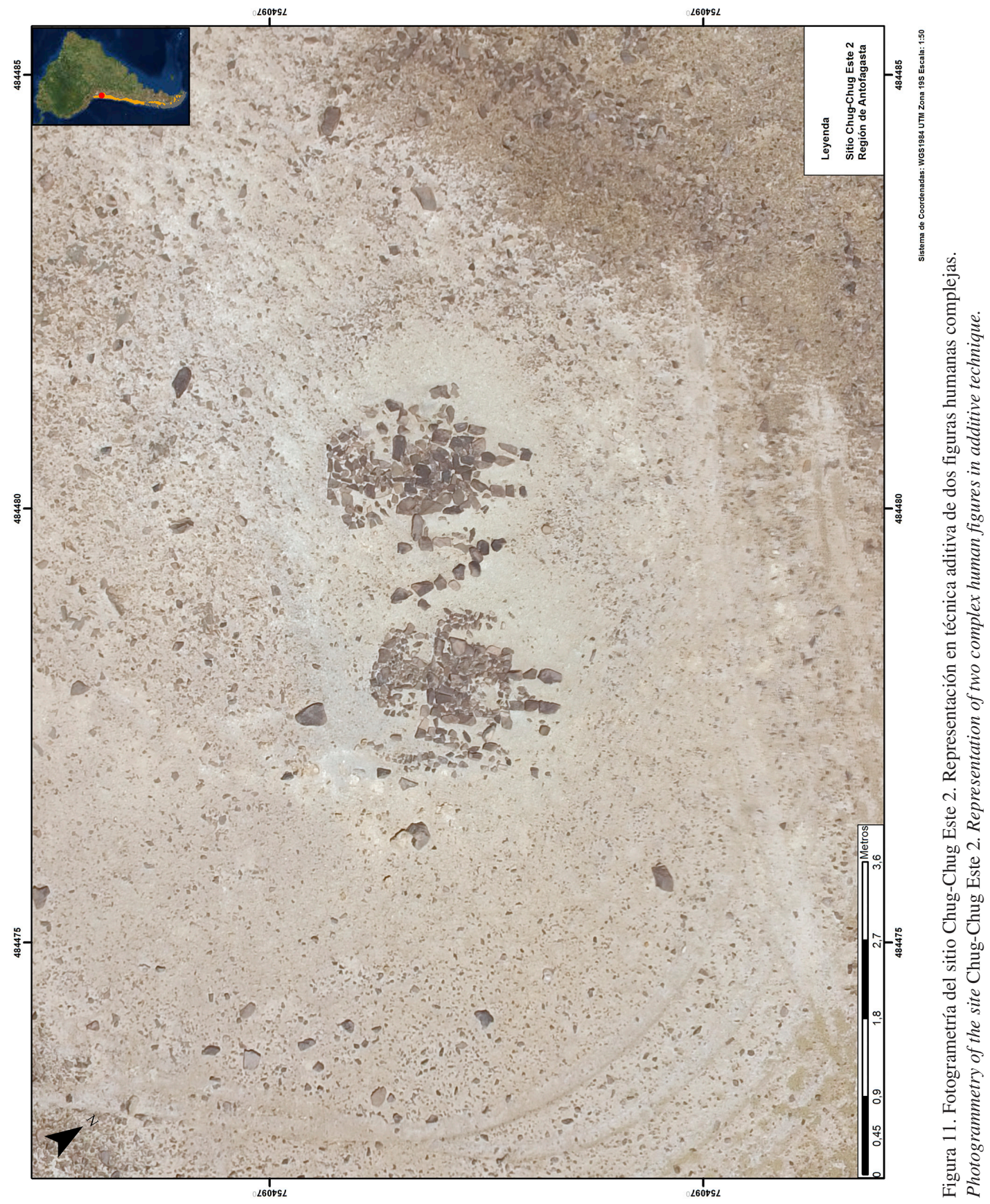




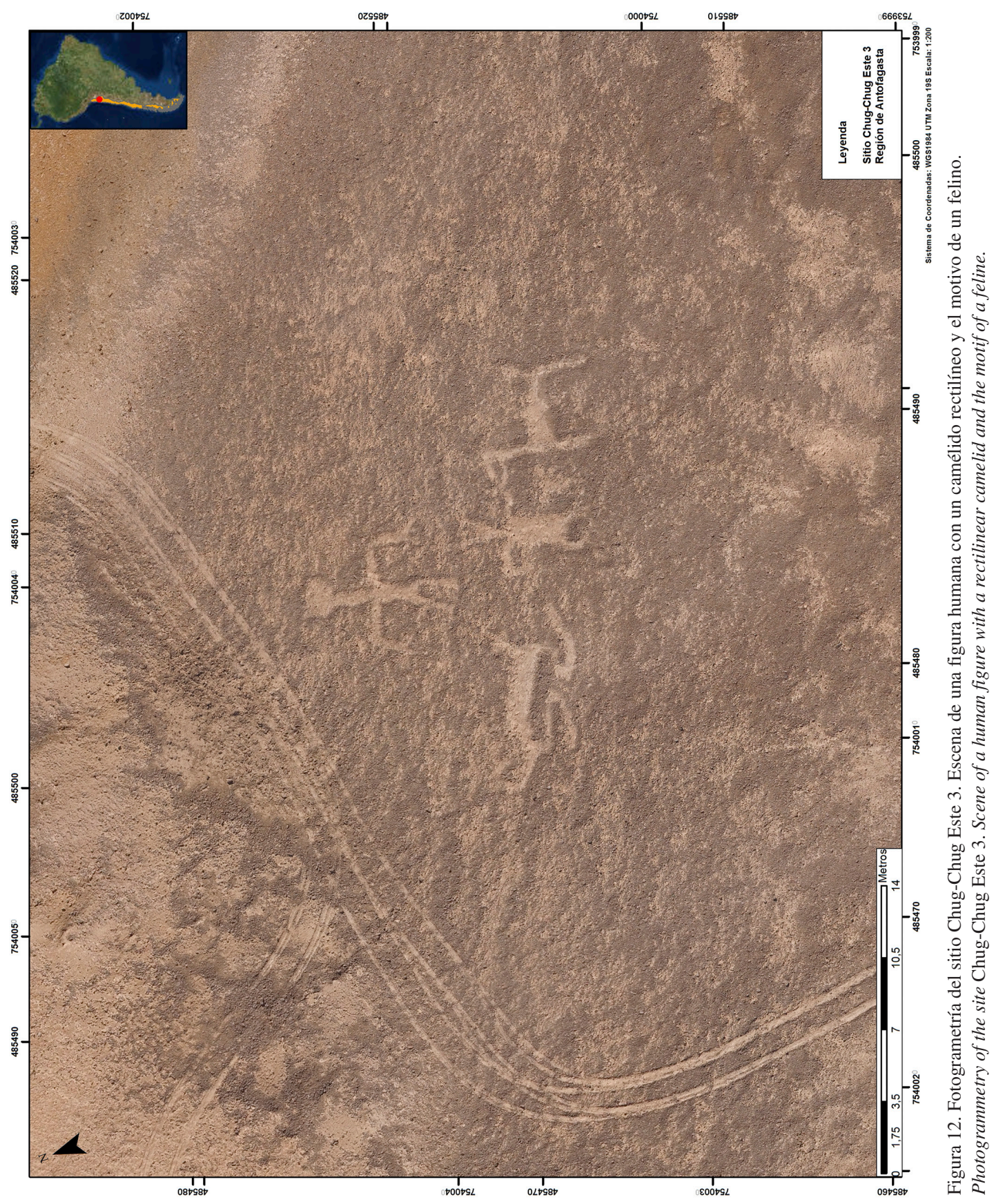




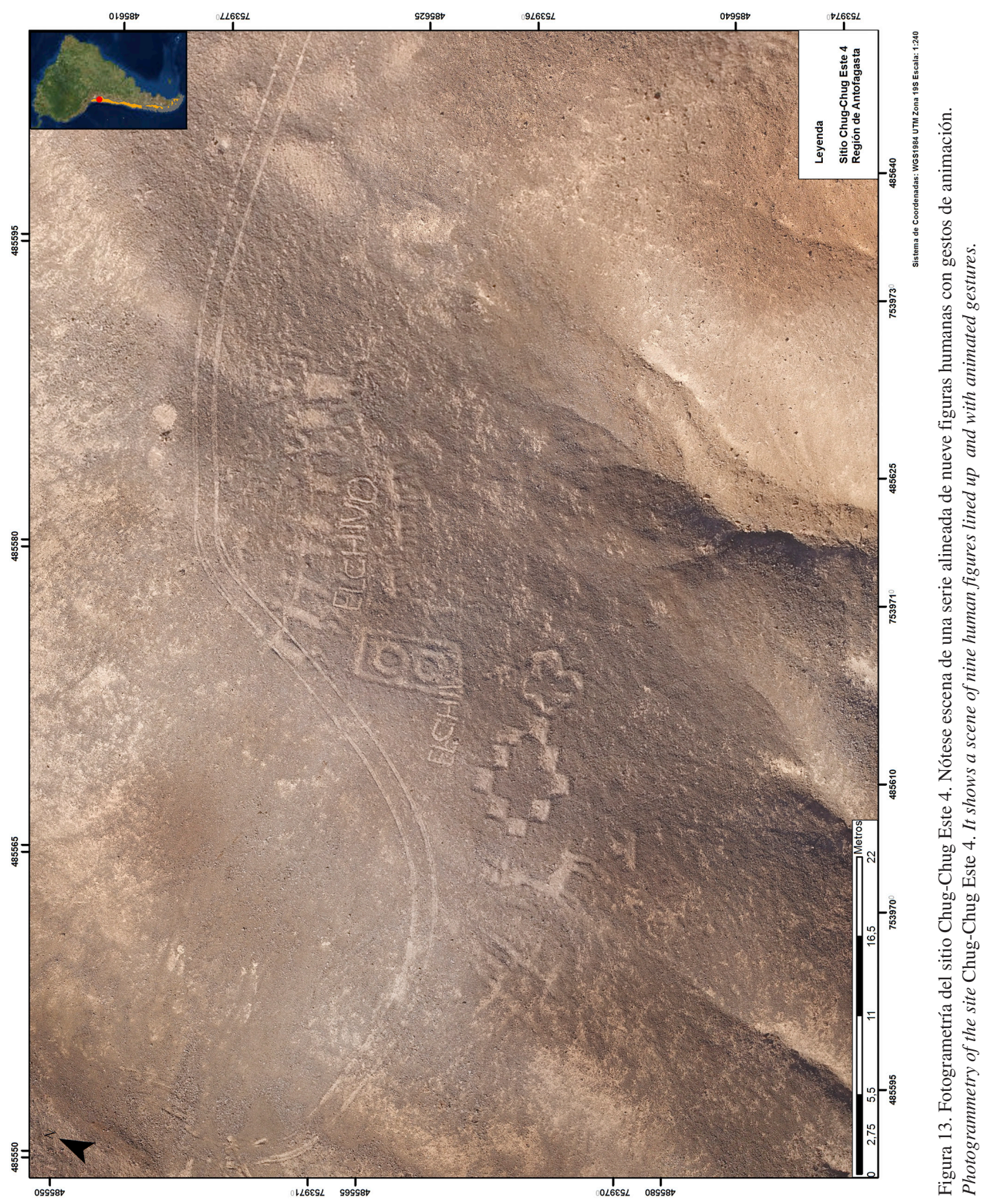


visibilidad como indicador grupal (Pimentel 2011). Túnicas y tocados son los indicadores más claros de lo anterior, pudiendo distinguirse seis tipos de vestimentas (trapezoidal, rectangular, cuadrada, cóncava, convexa y circular) y siete tipos de tocados (trapezoidal recto, trapezoidal curvo, semilunar, tumiforme, triangular, rectangular y de lados curvos), delatando por sí mismos la alta significancia que tuvieron como sistema visual de diferenciación entre las distintas unidades sociales interactuantes que hicieron uso de esta vía (Figura 14).

\section{Discusión y Conclusiones}

Resulta notorio que la Ruta de Chug-Chug tuvo una significativa historia de uso que se remonta a lo menos al período Formativo y que continuó en toda la secuencia posterior prehispánica, colonial y republicana. Particularmente para el Formativo Tardío (ca. 100-500 d.C.), se aprecia una primera mayor intensidad de la movilidad, manteniéndose desde entonces como uno de los corredores viales más usados y estables para conectar las regiones de Tarapacá y Atacama, con evidencias directas de bienes de esta época que procedían de ambas regiones. Los datos son elocuentes en confirmar que el movimiento de bienes, personas e ideas desde la región de Tarapacá hacia el Loa tuvo una larga tradición y que Chug-Chug, ubicado en sus intersticios sociales y liminales, concentra buena parte de la historia de la circulación, el intercambio y especialmente nos brinda luces sobre las relaciones entre Tarapacá y Atacama.

No se observó la presencia directa de grupos costeros del Pacífico en estas cotas y la información recabada más bien da cuenta de que se trató de un derrotero más exclusivo de grupos caravaneros. A diferencia por ejemplo de los contextos costeros que hemos analizado en la pampa de Calate y de El Toco, en los que la presencia costera es notable (Pimentel et al. 2011, 2017), aquí el único rasgo que los vincula más directamente con individuos de la costa son las Líneas de Piedras que encontramos en el sitio Abra Norte de Chug-Chug, en el extremo poniente del área de estudio y quizás marcando con ello el límite oriental de la presencia de los viajeros costeros en Chug-Chug. Por lo mismo resulta muy sugerente que se encuentren en el mismo sitio que reúne la mayor diversidad de tipos de prácticas ceremoniales y en el que se disputó visualmente las laderas entre geoglifos y líneas de piedras.
Del Período Medio (ca. 500-900 d.C.) destacaron las tradicionales vasijas negras pulidas que se vinculan con los oasis de San Pedro de Atacama, aunque la identificación de un fragmento de kero Tiwanaku en el sitio Abra Norte nos sugiere que a través de San Pedro de Atacama se insertaron en otros nodos de cotas más bajas distintos bienes procedentes del estado altiplánico, siendo Chug-Chug parte de una red interactiva que integró bienes que venían de más de 600 km de distancia. Situación distinta es la que da cuenta el período Intermedio Tardío (ca. 900-1450 d.C.), con una clara mayor intensificación sobre el uso de la vía de Chug-Chug y en particular sobre la presencia tarapaqueña en esta vía. En efecto, de este último período contamos con la mayor cantidad de evidencias, tanto de sitios habitacionales, ceremoniales, como figuras de geoglifos. Los campamentos son representativos sobre todo de la movilidad caravanera del Intermedio Tardío, aunque mostrando en ese sentido características muy similares a los períodos anteriores, con una logística e infraestructura bastante mínima que sugiere que en esta época la movilidad transdesértica continuaba estando a cargo de pequeños contingentes caravaneros. Especialmente destacable es el nivel de intensidad y diversidad de las prácticas rituales de los viajeros que son representativas de este período, siendo Chug-Chug donde hemos podido reconocer la mayor cantidad y variedad con respecto a todas las vías que conocemos. En un contexto de conflictos generalizados en todos los Andes y con la inevitable incertidumbre social asociada, resulta muy significativa tal intensidad ritual en el tránsito. La marcada regionalización y homogeneización que impera en todos los niveles sociales parece disolverse finalmente en las prácticas rituales de los viajeros, quizás como un modo de reforzar, en el otro sentido, la mantención de una ortodoxia ancestral de sistemas de diferenciación intrarregional que se estaba diluyendo aceleradamente.

Para los períodos tardíos (ca. 900-1540 d.C.) se reconoció una importante diversidad de tipos alfareros que dan cuenta principalmente de tradiciones atacameñas, seguida de las tradiciones tarapaqueñas, del altiplano meridional y del río Grande de San Juan, al sur de Bolivia, incluso con evidencias de una vasija cuzqueña imperial que lo vinculan con el estado Inca. Chug-Chug, por lo tanto, debió ser recorrido por una diversidad de viajeros con distintos orígenes, lenguas y procedencias. Sin embargo, pese a esta multiculturalidad, no se observaron síntomas 


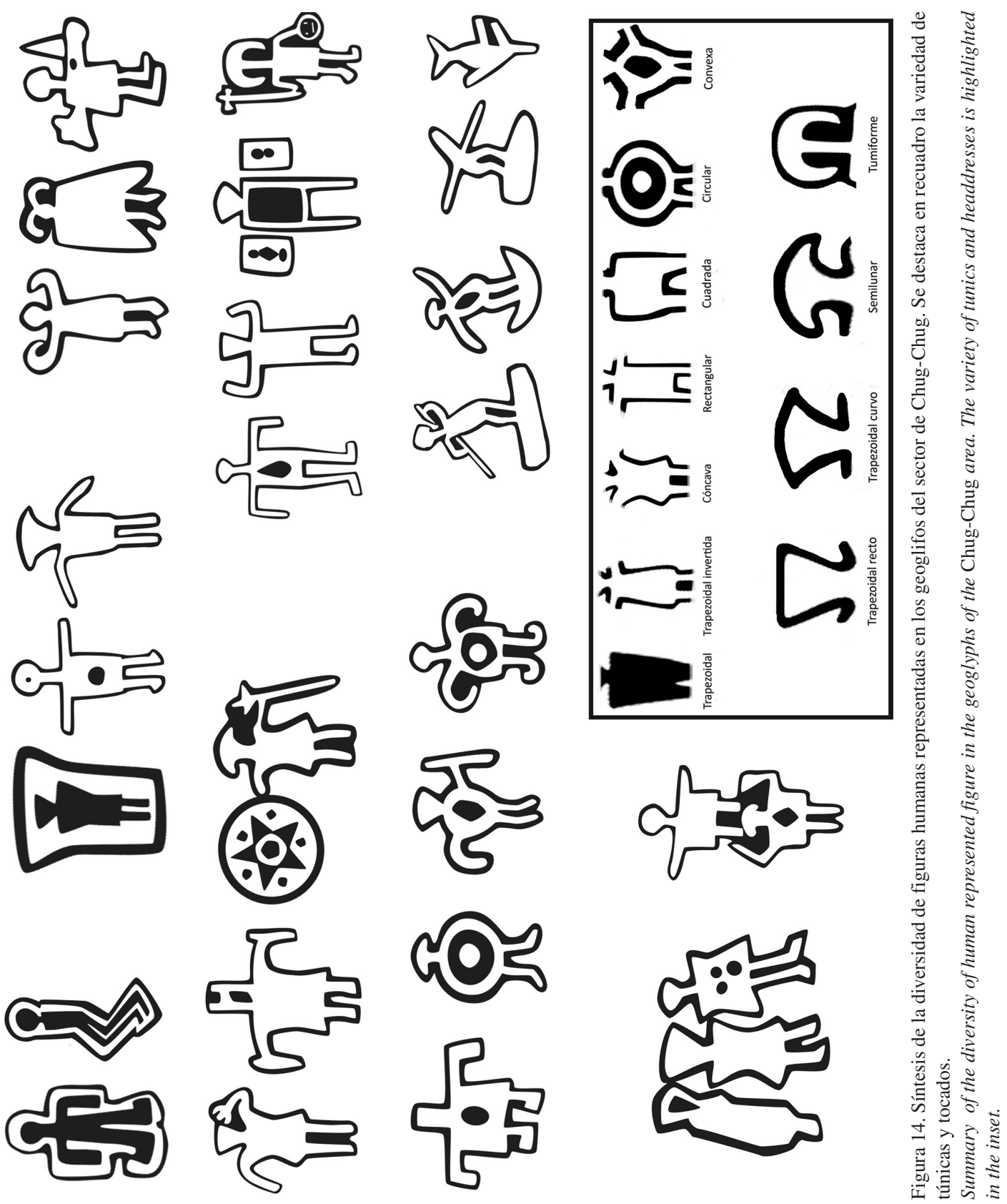


de conflictos, contrariamente a lo que se identifica para la misma época en la mayor parte de los Andes, denotando la particularidad del proceso interactivo en las cotas más bajas del desierto. Por ejemplo, no se consignó ni un solo viajero fallecido en todo este tramo y no se observaron gestos de supresión de determinadas figuras de geoglifos, que podrían ser dos indicadores de eventuales conflictos. De hecho, más bien lo que nos muestran los geoglifos es que existió un respeto tácito por las imágenes inscritas, una delicada y dedicada relación en las que debieron asignársele generalizadamente una particular significación a las figuras y a los propios cerros de Chug-Chug.

En definitiva, más que evidencias de violencia o de conflictos abiertos entre las sociedades de Atacama y Tarapacá, lo que se visualiza es una mayor intensidad de la circulación entre estas regiones y asimismo una magnificación de los geoglifos como sistema de comunicación, cuyo mensaje nos da cuenta significativamente de la notable intencionalidad de representar y visualizar a grupos específicos a través de la inscripción de ciertos elementos extrasomáticos en las figuras humanas tardías. Funcionando éstas como verdaderos emblemas a través de las cuales se desplegaron visualmente las distinciones e identificaciones societales y como un recurso potente de las disputas simbólicas sobre estos espacios liminales de tránsito multicultural.

Agradecimientos: Esta investigación ha sido posible gracias a la colaboración de los proyectos Fondecyt 1160045 y 1090762, PAI 79140041 y FONDART 70126. Corresponde a una síntesis del trabajo doctoral y postdoctoral desarrollado por el primer autor en el sector de Chug-Chug. Se agradece al equipo de terreno: a Wilfredo Faúndez, Magdalena García, Rodrigo Lorca, Nicole Fuenzalida, Claudia Castillo, Charles Rees, Sussy Rodríguez, Alex San Francisco, Lorena Arancibia y Francisca Gili. Al equipo profesional de la Fundación Desierto de Atacama, y especialmente a Jaime Sáez quien estuvo a cargo de la fotogrametría y cartografía del proyecto, a Juan Gili que colaboró con los dibujos y a Javier Arévalo quien aportó con el manejo del Dron y las bases de datos. Consejo de Monumentos Nacionales Orden No 3470, 18 de agosto del 2009. Finalmente, nuestro especial agradecimiento a Axel Nielsen por sus observaciones al manuscrito y a los evaluadores anónimos.

\section{Referencias Citadas}

Agüero, C. 2015. Vestuario y Sociedad Andina. Desarrollo del Complejo Pica-Tarapacá (800-1400 DC). Qillqa Ediciones IAA, Universidad Católica del Norte, San Pedro de Atacama.

Albornoz, C. 1989 [ca. 1582]. Instrucción para descubrir todas las guacas del Pirú y sus camayos y haciendas. En Fábulas y Mitos de los Incas, editado por E. Urbano y P. Duviols. Crónicas de América 48, Madrid.

Berenguer, J. 1994. Asentamientos, caravaneros y tráfico de larga distancia en el norte de Chile: El caso de Santa Bárbara. En De Costa a Selva: Intercambio y Producción en los Andes Centro-Sur, editado por M.E. Albeck, pp. 17-50. Instituto Interdisciplinario Tilcara y Universidad de Buenos Aires, Buenos Aires.

Berenguer, J. 1995. Impacto del caravaneo prehispánico tardío en Santa Bárbara. Hombre y Desierto 9:185-202.

Berenguer, J. 1999. El evanescente lenguaje del arte rupestre. En Arte rupestre de los Andes de Capricornio, editado por $\mathrm{J}$. Berenguer y F. Gallardo, pp. 9-56. Museo Chileno de Arte Precolombino, Santiago.

Berenguer, J. 2004. Tráfico de Caravanas, Interacción Interregional y Cambio Cultural en la Prehistoria Tardía del Desierto de Atacama. Ediciones Sirawi, Santiago.

Berenguer, J., V. Castro, C. Aldunate, C. Sinclaire y L. Cornejo 1985. Secuencia del arte rupestre en el alto Loa: una hipótesis de trabajo. En Estudios en Arte Rupestre, editado por C. Aldunate, J. Berenguer y V. Castro, pp. 87-108. Museo Chileno de Arte Precolombino, Santiago.

Bertonio, L. 1984 [1612]. Vocabulario de la Lengua Aymara. Ediciones Ceres, Cochabamba.

Briones, L. 2006. The geoglyphs of the north Chilean desert: an archaeological and artistic perspective. Antiquity 80:9-24.

Briones, L. y C. Castellón 2005. Catastro de Geoglifos. Provincia de Tocopilla, Región de Antofagasta. Fondo de Desarrollo de las Artes y la Cultura, Consejo Nacional de la Cultura y las Artes, Antofagasta.

Correa, I. y M. García 2014. Cerámica y contextos de tránsito en la ruta Calama-Quillagua, vía Chug-Chug, desierto de Atacama, norte de Chile. Chungara Revista de Antropología Chilena 46:25-50.

Gallardo, F., C. Sinclaire y C. Silva 1999. Arte rupestre, emplazamiento y paisaje en la cordillera del Desierto de Atacama. En Arte Rupestre en los Andes de Capricornio, editado por J. Berenguer y F. Gallardo, pp.57-96. Museo Chileno de Arte Precolombino, Santiago.

Gallardo, F., G. Cabello, G. Pimentel, M. Sepúlveda y L. Cornejo 2012. Flujos de información visual, interacción social y pinturas rupestres en el desierto de Atacama (norte de Chile). Estudios Atacameños 43:35-52. 
González Holguín, D. 1952 [1608]. Vocabulario de la Lengua General de Todo el Perú, Llamada Quechua. Edición del Instituto de Historia, Universidad Nacional de San Marcos, Lima.

Nielsen, A. 1997. El tráfico caravanero visto desde la Jara. Estudios Atacameños 14:339-372.

Nielsen, A. 2001. Evolución social en Quebrada de Humahuaca (700-1536 DC). En Historia Argentina Prehispánica, editado por E. Berberián y A. Nielsen, pp. 171-263. Editorial Brujas, Córdoba.

Nielsen, A. 2006. Estudios internodales e interacción interregional en los Andes Circumpuneños: Teoría, método y ejemplos de aplicación. En Esferas de Interacción Prehistóricas y Fronteras Nacionales Modernas en los Andes Sur Centrales, editado por $\mathrm{H}$. Lechtman, pp. 29-62. Instituto de Estudios Peruanos e Institute of Andean Research, Lima.

Nielsen, A. 2007. Armas significantes: tramas culturales, guerra y cambio social en el sur andino prehispánico. Boletín del Museo Chileno de Arte Precolombino12:9-41.

Núñez, L. 1984. Tráfico de Complementariedad de Recursos entre las Tierras Altas y el Pacífico en el Área Centro Sur Andina. 2 vol. Tesis para optar al grado de Doctor en Antropología, Departamento de Antropología Cultural, Universidad de Tokio, Tokio.

Núñez, L., C. Agüero, B. Cases y P. De Souza 2003. El campamento minero Chuquicamata-2 y la explotación cuprífera prehispánica en el Desierto de Atacama. Estudios Atacameños 25:7-34.

Pimentel, G. 2009. Las huacas del tráfico. Arquitectura ceremonial en rutas prehispánicas del Desierto de Atacama. Boletín del Museo Chileno de Arte Precolombino 14:9-38.

Pimentel, G. 2011. Geoglifos e imaginarios sociales en el Desierto de Atacama (Región de Antofagasta, Chile). En Temporalidad, Interacción y Dinamismo Cultural. La Búsqueda del Hombre. Homenaje al Profesor Lautaro Núñez Atencio, editado por A. Hubert, J.A. González y M. Pereira, pp. 163-200. Ediciones Universitarias Universidad Católica del Norte, Antofagasta.

Pimentel, G. 2013. Redes Viales Prehispánicas en el Desierto de Atacama. Viajeros, Movilidad e Intercambio. Tesis para optar al Grado de Doctor en Antropología. Universidad Católica del Norte y Universidad de Tarapacá, San Pedro de Atacama.
Pimentel, G. e I. Montt 2008. Tarapacá en Atacama. Arte rupestre y relaciones intersocietales entre el 900 y 1450 DC. Boletín del Museo Chileno de Arte Precolombino 13:35-50.

Pimentel, G. y M. Ugarte 2017. La agencia costera en la Pampa del Desierto de Atacama. En Monumentos Funerarios de la Costa del Desierto de Atacama. Contribuciones al Intercambio de Bienes e Información entre Cazadores-Recolectores Marinos (Norte de Chile), editado por F. Gallardo, B. Ballester y N. Fuenzalida. Centro Interdisciplinario de Estudios Interculturales e Indígenas y Sociedad Chilena de Arqueología, Santiago. En Prensa.

Pimentel, G., M. Ugarte, J. Blanco, Ch. Torres-Rouff y W. J. Pestle 2017. Calate. De lugar desnudo a laboratorio arqueológico de la movilidad y el tráfico multicultural prehispánico en el desierto de Atacama (ca. 7000 AP-550 AP). Estudios Atacameños. En Prensa.

Pollard, G. 1970. The Cultural Ecology of Ceramic Stage Settlement in Atacama Desert. Ph.D. Dissertation, University Microfilms Int., Columbia University, Ann Arbor.

Sinclaire, C. 1994. Los sitios de "Muros y Cajas" del río Loa y su relación con el tráfico de caravanas. En Taller de Costa a Selva, editado por M.E. Albeck, pp.51-76. Instituto Interdisciplinario Tilcara, Universidad de Buenos Aires, Buenos Aires.

Soto, C. 2011. Cuentas en el camino: aproximación tipológica a los objetos perforados en rutas del Desierto de Atacama, II Región, Chile. Informe Fondecyt N ${ }^{\circ}$ 1090762. Manuscrito en poder del autor.

Thomas, C. 1978. Estudio arqueológico del poblamiento tardío de Chiuchiu. Revista Chilena de Antropología 1:85-104.

Torres-Rouff, C., G. Pimentel y M. Ugarte 2012. ¿Quiénes viajaban? Investigando la muerte de viajeros prehispánicos en el Desierto de Atacama (ca. 800 AC-1536 DC). Estudios Atacameños 43:167-186.

Uribe, M. 2006. Acerca de complejidad, desigualdad social y el Complejo Cultural Pica-Tarapacá en los Andes Centro-Sur (1000-1450 DC). Estudios Atacameños 31:91-114.

Valcárcel, L. 1964. Etnohistoria del Perú Antiguo. Universidad Nacional Mayor de San Marcos, Lima.

\section{Notas}

1 Se debe precisar que cuando nos referimos en todo el texto a tarapaqueños (Tarapacá) o área atacameña (Atacama), lo ocupamos con un sentido netamente operacional para dar cuenta de las poblaciones prehispánicas que habitaban las actuales regiones de Tarapacá y de Antofagasta.

2 Saliendo desde Calama, cada uno de estos sitios están a una distancia muy regular de unos $20 \mathrm{~km}$ desde el punto anterior. Distancia Calama-quebrada Montecristo- $1=20$ km; quebrada Montecristo-1-ChugChug-1 = 19,3 km; ChugChug-1-Abra Norte-2 $=18,2 \mathrm{~km}$.
3 En el diccionario Aymara de Bertonio (1612), La raíz cama significa "todos los de una especie o género de cualquier cosa"; Cchama = Fuerza; Chica = mitad de algo. En el diccionario Quechua de González Holguín (1608) Cama tiene cuatro significados distintos: Cama $=$ Hasta; Cama = Todo sin quedar nada como ccari Cama. "Todos varones y con verbos. Rincamam. Todos van"; Cama= "Segun o conforme. Yuyayniy Cama. Conforme a mí sentir y juyzio"; Cama $=$ "El pecado, o culpa. Camallicuk o huchallicuk. El pecador". Según Valcárcel (1964:105) Camachico es la asamblea de todos los miembros de una comunidad. 